\title{
Recent advances in $\mathrm{TiO}_{2}$ nanoarrays/graphene for water treatment and energy conversion/storage
}

\author{
Yanhua $\mathrm{Fan}^{1,2^{*}}$, Guangwu $\mathrm{Hu}^{2}$, Shuaiqin $\mathrm{Yu}^{1}$, Liqiang $\mathrm{Mai}^{{ }^{2 *}}$ and $\mathrm{Lin} \mathrm{Xu}^{2}$
}

\begin{abstract}
Although $\mathrm{TiO}_{2}$-based nanostructures with unique chemical and physical properties exhibit great promise in water treatment and energy conversion/storage, there still exist some limitations. In order to further improve the photochemical properties, one-dimension $\mathrm{TiO}_{2}$ nanoarrays on the substrate are primarily combined with graphene by various preparation technologies. The composite coating has exhibited extraordinary photocatalytic abilities in the degradation of organic pollutants into less toxic compounds, antimicrobial activity and adsorption capacity in water treatment. Especially, it is easy to recycle after photocatalytic reaction. Additionally, $\mathrm{TiO}_{2}$ nanoarrays/graphene on the substrate (especially flexible substrate) could provide potential opportunities for flexible-device fabrication with excellent photovoltaic conversion efficiency and electrochemical performance in energy conversion/storage devices. As far as we know, the relevant reviews have rarely been reported. Here, we present a comprehensive review on the preparation of $\mathrm{TiO}_{2}$ nanoarrays or $\mathrm{TiO}_{2}$ nanoarrays/graphene, and their application and mechanism in water treatment and energy conversion/storage.
\end{abstract}

Keywords: $\mathrm{TiO}_{2}$ nanoarrays, graphene, photocatalysis, water treatment, energy conversion/storage

\section{INTRODUCTION}

While incredible progress in science and technology has indeed raised the quality and standard of human life and health, a multitude of problems have been brought about as well, such as energy shortage and environmental problem. Among them, water pollution is one of the biggest and the most alarming problems which demands formidable and effective solutions [1]. In the sea and lake, algal bloom caused by the eutrophication of the water, causes many concerns about water quality, because the presence of cyanobacteria can potentially produce toxins named cyanotoxins and off-odor compounds. Microcystins (MCs) are the most widespread cyanotoxins which exist in diverse aqueous environments [2]. MCs in water can cause acute and chronic toxicity to humans, bringing about mortality, loss of production, and decrement of productivity in aquaculture, and they also have the potential to harm consumers through the food web, via accumulation in freshwater fish [2]. In the recent years, there was a noticeable increase in the frequency of harmful algae blooms outbreaks in the sea and lake. Although huge initiatives have been already adopted to tackle the problem, further and thorough research dedicated to this issue is still required.

Moreover, in the case of water treatment technology, there are biodegradable technology, coagulation/precipitation techniques, and Fenton oxidation treatment technology [3-8], which are shown in Table 1. Although the treatment efficiency of these methods is high, the use of chemicals will bring about other environmental problems such as pipe blockages and water deterioration. Therefore, the advanced technology using photocatalysis is attracting more attention, owing to $\cdot \mathrm{OH}$ with strong oxidizing properties, which completely degrades almost all organic pollutants and has great antimicrobial activities in water treatment [9].

Simultaneously, the ever-increasing demand for energy is accompanied by the rapid growth of the global population and urbanization. Rapid energy consumption has resulted in the search for green and renewable alternative energy solutions. Ideally, solar energy, a clean and inexhaustible energy source, has great potential to meet the stringent energy demands [10]. Fundamentally, how to efficiently utilize and convert abundant solar energy remains a significant and urgent challenge for researchers. Solar cells are regarded as a suitable choice for harnessing and utilizing sunlight to drive chemical

${ }^{1}$ College of Ocean Science and Engineering, Shanghai Maritime University, Shanghai 200135, China

${ }^{2}$ State Key Laboratory of Advanced Technology for Materials Synthesis and Processing, Wuhan University of Technology, Wuhan 430070, China

*Corresponding authors (emails: mlq518@whut.edu.cn (Mai L); fyhxu2003@163.com (Fan Y)) 
Table1 Comparing the advantages and disadvantages of photocatalytic system and existing water treatment methods $[4,7,8]$

\begin{tabular}{|c|c|c|}
\hline & Advantage & Disadvantage \\
\hline Biological treatment technique & $\begin{array}{l}\text { (1) High reliability of the method } \\
\text { (2) High load operation can be processed }\end{array}$ & $\begin{array}{l}\text { (1) Efficiency is low } \\
\text { (2) Limited by biological species }\end{array}$ \\
\hline Coagulation/precipitation & (1) High efficiency of processing & $\begin{array}{l}\text { (1) Pipe blockages and water deterioration } \\
\text { (2) Environmental problems }\end{array}$ \\
\hline Fenton oxidation technology & $\begin{array}{l}\text { (1) } \mathrm{OH} \text { break down organic pollutants } \\
\text { (2) Process is simple and easy to manage }\end{array}$ & $\begin{array}{l}\text { (1) Limited by the Fenton's reagent } \\
\text { (2) Remove the iron salts } \\
\text { (3) Need the acidic conditions, } \mathrm{pH}<4\end{array}$ \\
\hline Photocatalytic oxidation technology & $\begin{array}{l}\text { (1) Complete waste water treatment is possible } \\
\text { (2) Low cost } \\
\text { (3) Green, friendly to environment } \\
\text { (4) Antimicrobial and degrading all compounds }\end{array}$ & $\begin{array}{l}\text { (1) Limited by UV absorption } \\
\text { (2) Photocatalyst powder is difficult to recover }\end{array}$ \\
\hline
\end{tabular}

reactions and produce electricity. Additionally, energy storage such as lithium-ion batteries (LIBs) has also been widely applied in portable digital products instead of the consumption of fossil fuels [11]. However, the energy density of LIBs is inadequate to satisfy the continuous growth in demand. It is essential to explore cathode/ anode materials with high specific capacity, excellent rate capability and long cycle life.

$\mathrm{TiO}_{2}$ is widely used mainly due to its non-toxicity, hydrophilicity, low cost, high photocatalytic activity, strong optical absorption, high chemical stability, and its suitable flat band potential $\left(V_{\mathrm{fb}}\right)$ that can induce desired redox reactions without bias potential $[12,13]$. The excitation of $\mathrm{TiO}_{2}$ by photons with light energy greater than the band gap is the primary process underlying its vast area of photochemistry and photoelectrochemistry, as shown in Fig. 1 [14]. Therefore, $\mathrm{TiO}_{2}$ has attracted significant attention because of its promising applications in wastewater purification as well as energy conversion/storage. The various applications of $\mathrm{TiO}_{2}$ photocatalysis in recent years are shown in Fig. 2.

In the case of the advanced water treatment technology, the photocatalytic $\mathrm{TiO}_{2}$ produces reactive oxygencontaining radicals $\left(\cdot \mathrm{OH}, \cdot \mathrm{OOH}, \cdot \mathrm{O}_{2}^{-}\right)$. Among them, the hydroxyl radical $(\cdot \mathrm{OH})$ is the most reactive and powerful oxidant that decomposes the organic compounds into relatively harmless compounds, such as $\mathrm{CO}_{2}$, $\mathrm{H}_{2} \mathrm{O}$, as shown in Table 2 [15]. In addition, the operating cost can be reduced dramatically. However, $\mathrm{TiO}_{2}$ particles, the typical photocatalytic materials, have some shortcomings in the process. Firstly, $\mathrm{TiO}_{2}$ can be only activated under the irradiation with photons of light in the UV domain $(\leq 387 \mathrm{~nm})$, and thus the light utilization efficiency to solar irradiation is limited, which causes the low photocatalytic properties. Secondly, when used as photocatalyst, particles have some disadvantages, such as

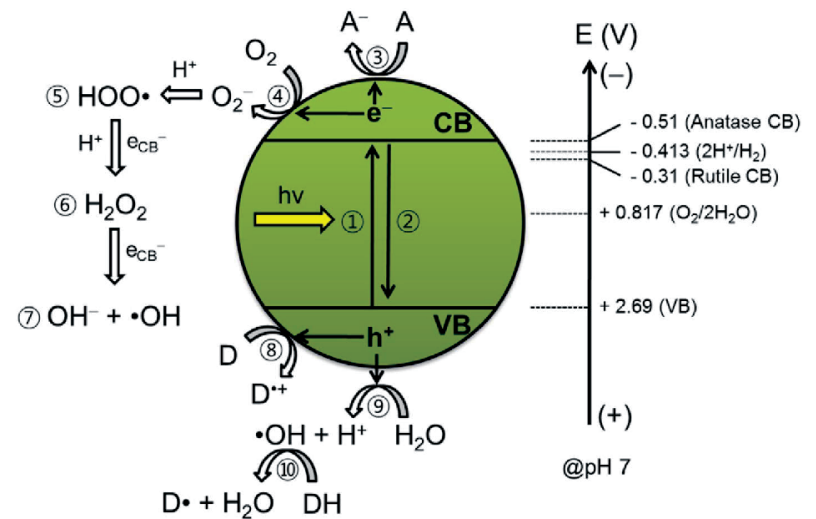

Figure 1 Schematic illustration for energetics and primary reaction mechanism of $\mathrm{TiO}_{2}$ photocatalysis. 1: Bandgap $\left(E_{\mathrm{g}}\right)$ excitation and electron-hole charge pair creation, 2: the charge pair recombination, 3: electron transfer to electron acceptor (A: usually dissolved oxygen), 4: electron transfer to oxygen molecule, 5: formation of hydroxyperoxyl radical via a reductive pathway, 6: formation of hydrogen peroxide, 7: formation of hydroxyl radical, 8: hole transfer to electron donor (D: usually organic pollutants), 9: hole transfer to surface hydroxyl group to generate $\mathrm{OH}$ radical, 10: hydroxyl radical-mediated oxidation of organic substrate. Note that the energy levels (right arrow) shift according to the Nernst equation: $E\left(\mathrm{~V}_{\mathrm{NHE}}\right)=E^{0}(@ \mathrm{pH} 0)-0.059 \mathrm{pH}$. Reprinted with permission from Ref. [14], Copyright 2013, Elsevier.

the particle defects, large grain boundaries, surface states and a low light response. These undesirable phenomena might decrease the electron transport rate, and eventually lead to poor charge collection efficiency. Additionally, $\mathrm{TiO}_{2}$ particles are difficult to disperse, and are not easy to recover after photocatalytic reaction, which cause environmental pollution. Therefore, it is necessary to introduce a novel form of $\mathrm{TiO}_{2}$ to solve these problems.

One-dimensional (1D) $\mathrm{TiO}_{2}$ nanostructures, including nanorods [16,17], nanowires [18], nanotubes [19,20], nanofibers [21] and nanobelts [22], are recognized as one of the most promising materials to provide a direct electric transport pathway for efficient charge collection 


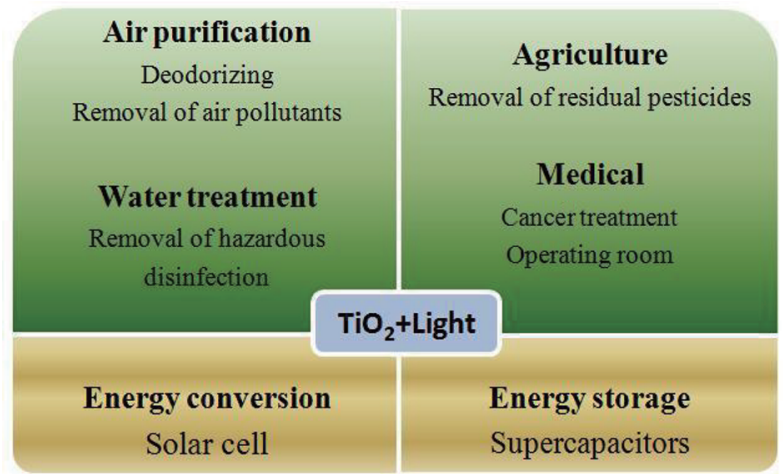

Figure 2 Various applications of $\mathrm{TiO}_{2}$ photocatalysis in environment and energy fields.

Table 2 Redox potential of major oxidizing agents used in water treatment technology. Reprinted with permission from Ref. [8], Copyright 2017, Elsevier

\begin{tabular}{ccc}
\hline Oxidizing agent & $\begin{array}{c}\text { Oxidation potential } \\
(\mathrm{V})\end{array}$ & $\begin{array}{c}\text { Relative oxidation } \\
\text { power }\end{array}$ \\
\hline OH radical & 2.80 & 2.06 \\
Ozone & 2.07 & 1.52 \\
Hydrogen peroxide & 1.77 & 1.30 \\
Perhydroxyl radical & 1.70 & 1.25 \\
Permanganate & 1.68 & 1.24 \\
Chlorine dioxide & 1.57 & 1.15 \\
Chlorine & 1.36 & 1 \\
Oxygen & 1.20 & 0.88 \\
\hline
\end{tabular}

[23]. Compared with their particles counterpart, 1D nanomaterials have unique chemical and physical properties which can be tailored by changing their nanoscaled 1D morphologies [24]. Firstly, the 1D nanostructures facilitate fast electron transport along the longitudinal dimension, significantly improving the charge separation efficiency; secondly, 1D nanoarrays are expected to have a larger specific surface area and pore volume as compared with the corresponding powder materials, providing more active sites; thirdly, based on the high length-todiameter ratio for the 1D nanostructures, light absorption and scattering are thought to be significantly enhanced. In addition, fewer localized states due to the surface state of a specific facet of the nanocrystals also help to get the highly efficient photocatalysts. $1 \mathrm{D} \mathrm{TiO}_{2}$ nanostructures have shown outstanding performance and versatility in a wide range of applications [25-30]. Yu et al. [31] reported that 1D nanomaterial-based membranes possessing interconnected open pore structures and large surface areas, were widely used to remove oily contaminants, toxic metal ions, emulsions, nanoparticles, small organic molecules such as antibiotics and dyes from water. Especially, $1 \mathrm{D} \mathrm{TiO}_{2}$ nanoarrays on the substrate are not only very easy to recover after the photocatalytic reaction, but also can increase the electron transport rate, and then improve the photocatalytic properties. In order to further limit the recombination of photoelectron-hole pairs during excitation state and maximize the light absorption, graphene is primarily combined with $\mathrm{TiO}_{2}$ nanostructure by various preparation technologies. Furthermore, to highlight the research progress in the $1 \mathrm{D} \quad \mathrm{TiO}_{2}$ nanoarrays/graphene and promote their better use, it is necessary to summarize the $1 \mathrm{D} \mathrm{TiO}_{2}$ nanoarrays and their nanocomposite in water treatment and energy conversion/storage.

Recently, several reviews have discussed some aspects of $\mathrm{TiO}_{2}$-based nanomaterials and their applications $[1,11,23,29]$. However, review about $1 \mathrm{D} \mathrm{TiO}_{2}$ nanoarrays/graphene has rarely been reported until now. Here, we make great efforts to present a comprehensive review of $1 \mathrm{D} \mathrm{TiO}_{2}$ nanoarrays/graphene in water treatment and energy conversion/storage.

\section{DESIGN OF $\mathrm{TiO}_{2}$ NANOARRAYS/ GRAPHENE COMPOSITES}

Owing to the $3.2 \mathrm{eV}$ band gap of $\mathrm{TiO}_{2}$, its photocatalytic activity is restricted to the ultraviolet region. Several strategies such as doping [32,33], introduction of defects $[34,35]$ and combination with electron acceptor materials $[36,37]$, have been tried to reduce the band gap to make it active in visible region. Graphene is the preferred candidates as electron acceptors owing to its outstanding physical, chemical and electronic properties [38].

Graphene, a novel two-dimensional carbon material with only one atom thick, is considered as the thinnest and hardest material known so far. Owing to single layer of $\mathrm{sp}^{2}$ network of carbon atoms, graphene inherently displays a large number of intriguing and peculiar properties such as optical transparency, high room temperature charge carrier mobility $\left(100,000 \mathrm{~cm}^{2} \mathrm{~V}^{-1} \mathrm{~s}^{-1}\right)$, excellent mechanical strength $(2.4 \pm 0.4 \mathrm{TPa})$, theoretically large surface area $\left(2,630 \mathrm{~m}^{2} \mathrm{~g}^{-1}\right)$, high thermal conductivity $(2,000$ to $5,000 \mathrm{~W} \mathrm{~m} \mathrm{~K}^{-1}$ ) and high capacity sustained at large current density $\left(10^{8} \mathrm{~A} \mathrm{~cm}^{-2}\right)[1,39]$, which make it exceptionally suitable for electron acceptor in versatile applications. In the last two decades, the term "graphene" has been used loosely in the literature to represent pristine graphene, graphene oxide (GO), and reduced 
graphene oxide (rGO), which obtain immense interest among researchers and attract an inundation of studies devoted to various aspects of graphene [40].

Coupling $\mathrm{TiO}_{2}$ with graphene could greatly enhance the photocatalytic performance $[41,42]$. On the one hand, the electric field integrally formed at the heterojunction interface can effectively separate the photoelectrons-holes in $\mathrm{TiO}_{2}$ [43-46]. On the other hand, the combination of $\mathrm{TiO}_{2}$ with graphene leads to the reduction in band gap of the $\mathrm{TiO}_{2}$ by energy favored hybridization of $\mathrm{O}_{2 \mathrm{p}}$ and $\mathrm{C}_{2 \mathrm{p}}$ atomic orbitals which result in the formation of new valance band [36]. Compared to pure materials, $\mathrm{TiO}_{2} /$ graphene composite materials exhibit enhanced activities due to the synergistic effect of graphene and $\mathrm{TiO}_{2}[47-$ 49]. For instance, self-assembly of $\mathrm{TiO}_{2}$ nanorods on the graphene oxide sheets $\left(\mathrm{GO}-\mathrm{TiO}_{2}\right.$ NRCs) has been achieved by a water/toluene two-phase process. Compared with GO-P25 and the original $\mathrm{TiO}_{2}$ nanorods, the GO- $\mathrm{TiO}_{2} \quad \mathrm{NRCs}$ exhibit higher photocatalytic activity toward degradation of contaminant methylene blue and acid orange 7 under UV light irradiation [50]. Photocatalytic activities of the composite highly depend on the interface between $\mathrm{TiO}_{2}$ and graphene. An intense coupling between $\mathrm{TiO}_{2}$ nanorods and graphene facilitates charge separation and so retards the recombination of the photogenerated hole-electron pairs in the composite [51]. Therefore, coupling $\mathrm{TiO}_{2}$ nanoarray with graphene on the substrate has wonderful prospect in water treatment and energy conversion/storage, which deserves further rigorous research in the future.

In particular, some mechanisms of photocatalytic activities of $\mathrm{TiO}_{2}$ /graphene composites have been proposed. As a p-type semiconductor, graphene can act as extremely effective electron sinks, which can create a Schottky barrier at the $\mathrm{TiO}_{2}$ /graphene interface (a space charge region) [52]. $\mathrm{TiO}_{2}$ acts as an n-type semiconductor, but in the presence of graphene, photoinduced electrons may migrate freely to the graphene surfaces, which might have a lower Fermi level like a metal. Another possible mechanism is that graphene may act as a photosensitizer. This might be responsible for extending the $\mathrm{TiO}_{2}$ photocatalytic activity to the visible light range [53]. In addition, a range of hypotheses have also been proposed. Graphene is used as a two-dimensional photocatalyst owing to its excellent redox properties. High quality graphene makes the electrons travel without scattering at higher mobility than $15,000 \mathrm{~m}^{2} \mathrm{~V}^{-1} \mathrm{~s}^{-1}$ at room temperature, meaning that it acts as an ideal electron sinks and electron transfer bridge [54]. This is possibly because mobility that the conductivity is affected by the electron delocalized behaviors in the conjugated $\pi$ $\pi$ interaction of $\mathrm{TiO}_{2} /$ graphene composites, resulting in rapid photo-induced charge separation and slow charge recombination in the electron transfer process [55]. The band gap behavior of $\mathrm{TiO}_{2}$ /graphene composites has a wide range $(2.66-3.18 \mathrm{eV})$, according to the graphene content from 0.25 to $10 \mathrm{wt} . \%$ [56]. This suggests that the newly formed $\mathrm{Ti}-\mathrm{O}-\mathrm{C}$ bands of $\mathrm{TiO}_{2}$ /graphene composites can extend to the absorption edge, which can absorb the long wavelength light of the visible region [57].

\section{SYNTHETIC STRATEGIES OF $\mathrm{TiO}_{2}$ NANOARRAYS/GRAPHENE COMPOSITES}

In recent years, many researchers paid considerable attention to controlling the morphologies of $\mathrm{TiO}_{2}$ nanoarrays via various methods, since the size and shape of $\mathrm{TiO}_{2}$ nanoarrays determine the electrochemical properties and photocatalytic activities. $\mathrm{TiO}_{2}$ nanoarrays/graphene composite coating can be obtained in three different ways, one of which is coating the graphene dispersion on the substrate by spin coating, followed by growing the $\mathrm{TiO}_{2}$ nanoarrays on the graphene; the second way is coating the graphene dispersion on the $\mathrm{TiO}_{2}$ nanoarrays by spin coating. Additionally, sandwich-type $\mathrm{TiO}_{2}$ nanoarrays/graphene composite coating shown in Fig. $3 \mathrm{c}$, can also be obtained by coating graphene dispersion on the $\mathrm{TiO}_{2}$ nanoarrays grown on the graphene. Spin coating method is a simple technique where the loaded solvent drops on the center of substrate, and will be deposited uniformly under high speed rotation. A uniform thin film will be formed on the substrate by centrifugal force [40]. Therefore, it is very important to prepare $\mathrm{TiO}_{2}$ nanoarrays on the substrate, in order to prepare $\mathrm{TiO}_{2}$ nanoarrays/graphene composite coating.

To date, a variety of preparation methods have been developed for the synthesis of $\mathrm{TiO}_{2}$ nanoarrays, such as chemical vapor deposition [58], sol-gel method [59], template method [60], and hydrothermal/solvothermal method [61]. Among them, the hydrothermal method is very simple to produce $\mathrm{TiO}_{2}$ nanoarrays. For instance, as shown in Fig. 3, the sandwich heterostructures of $\mathrm{TiO}_{2}$ nanorods were obtained by hydrothermal method. Another efficient technique to prepare the graphene/ $\mathrm{TiO}_{2}$ composite with excellent photocatalytic properties is direct growth process. Recently, Xu et al. [62] reported that graphene quantum dots could directly grow on $3 \mathrm{D}$ micropillar/microwave arrays of rutile $\mathrm{TiO}_{2}$ nanorods to form the graphene- $\mathrm{TiO}_{2}$ composite. 


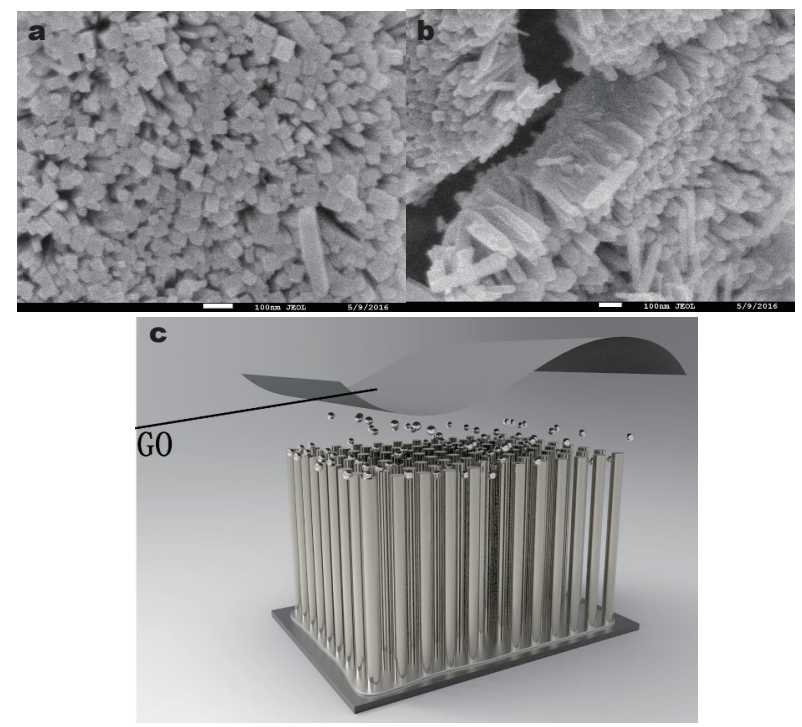

Figure 3 (a) Scanning electron microscopy (SEM) surface images and (b) SEM cross section images of $\mathrm{TiO}_{2}$ nanorods obtained by the hydrothermal route; (c) schematic of sandwich $\mathrm{GO} / \mathrm{TiO}_{2}$ nanorods/graphene heterostructures.

\section{Hydrothermal method/solvothermal method}

Hydrothermal processing refers to any heterogeneous reaction in the presence of aqueous solvents or mineralizers under high temperature and pressure conditions in a sealed or closed system. Solvothermal processing is almost the same as hydrothermal processing except that the solvent is nonaqueous. Thus, we put the two methods together, namely hydrothermal/solvothermal method.

Patel et al. [63] successfully synthesized $\mathrm{TiO}_{2}$ nanorods by hydrothermal method. This method was also employed by Lv et al. [64], where densely aligned $\mathrm{TiO}_{2}$ nanorod arrays with tunable thickness were synthesized. The property of substrates plays a key role in the synthesis of $\mathrm{TiO}_{2}$ nanorods array, and lots of substrates have been applied to support $\mathrm{TiO}_{2}$ nanorods. Liu et al. [65] introduced a mild hydrothermal method to fabricate single-crystalline rutile $\mathrm{TiO}_{2}$ nanorod arrays directly on fluorine-doped tin oxide substrates. Dubal et al. [66] synthesized polycrystalline rutile $\mathrm{TiO}_{2}$ nanorods by controlling precipitation routes on glass and indium tin oxide substrates.

The in situ growth of $\mathrm{TiO}_{2}$ on graphene or graphene on $\mathrm{TiO}_{2}$ can provide much more efficient hybrid photocatalysts. Wang et al. [67] developed a method for the in situ preparation of graphene-like carbon structures on $\mathrm{TiO}_{2}$ which show nearly 2.5 times enhanced photodegradation of methylene blue dye, when compared with pristine $\mathrm{P} 25 \mathrm{TiO}_{2}$. Liang et al. [68] reported the uniform growth of $\mathrm{TiO}_{2}$ nanocrystals directly on graphene oxide substrate via hydrolysis coupled hydrothermal treatment. The prepared $\mathrm{GO}-\mathrm{TiO}_{2}$ hybrids showed a three-fold photocatalytic activity for the degradation of Rhodamine B dye as compared to $\mathrm{P} 25 \mathrm{TiO}_{2}$. This enhancement was attributed to an improved electronic coupling between graphene oxide and $\mathrm{TiO}_{2}$ nanocrystals and the higher surface area of this hybrid material.

In addition, Zou et al. [69] prepared sandwich-like $\mathrm{TiO}_{2} /$ graphene $/ \mathrm{TiO}_{2}$ heterostructures by a simple and general nanocrystal-seed-directed hydrothermal route, which realized a large-scale growth of $\mathrm{TiO}_{2}$ nanorod arrays on both sides of flexible graphene sheets. They found that in the hydrothermal process, the $\mathrm{TiO}_{2}$ nanocrystals seeded on the graphene sheet played a key role in growth of the nanorod arrays on the graphene surfaces; the size of the $\mathrm{TiO}_{2}$ nanocrystal seeds on the graphene sheets had an obvious effect on the size of the nanorods. The photocatalytic property of the $\mathrm{TiO}_{2} / \mathrm{G} /$ $\mathrm{TiO}_{2}$ had been evaluated by the degradation of methylene blue under UV/vis irradiation. Compared with P25 and $\mathrm{TiO}_{2}$ nanorods, $\mathrm{TiO}_{2} / \mathrm{G} / \mathrm{TiO}_{2}$ catalysts exhibited remarkably enhanced photocatalytic activities, indicating that the heterostructures could serve as promising candidates for photocatalytic decontamination. Furthermore, for 1D $\mathrm{TiO}_{2}$ nanorod arrays, as shown in Fig. 4 [70], the recombination rate of $\mathrm{e}^{-}$and $\mathrm{h}^{+}$in $\mathrm{TiO}_{2}$ nanoarrays is lower than that in $\mathrm{TiO}_{2}$ nanoparticles, which would enhance the photocatalytic activity [71].

\section{Template-based synthesis method}

Usually, nanoarrays synthesized by this method have a well-defined size and shape, benefiting from the directing effect of the templates. The template-based synthesis method includes three primary steps: template preparation, synthesis of nanoarrays using the template and template removal. The most common templates for the preparation of $\mathrm{TiO}_{2}$ nanoarrays are anodized alumina membranes (AAMs). The template is placed in colloidal dispersions which are prepared by the sol-gel method. Then, the template pores are filled with the colloidal dispersions because of the capillary forces. Followed by drying and calcining, $1 \mathrm{D} \mathrm{TiO}$ arrays can be synthesized. However, it is difficult to guarantee the complete filling of the template pores.

Yuan et al. [72] successfully prepared $\mathrm{TiO}_{2}$ nanotube and nanowire arrays by this method. In this method, $\mathrm{Ti}\left(\mathrm{OC}_{4} \mathrm{H}_{9}\right)_{4}$ (TBT) dissolved in $n$-butyl alcohol and deionized water immersed the AAM template for six 

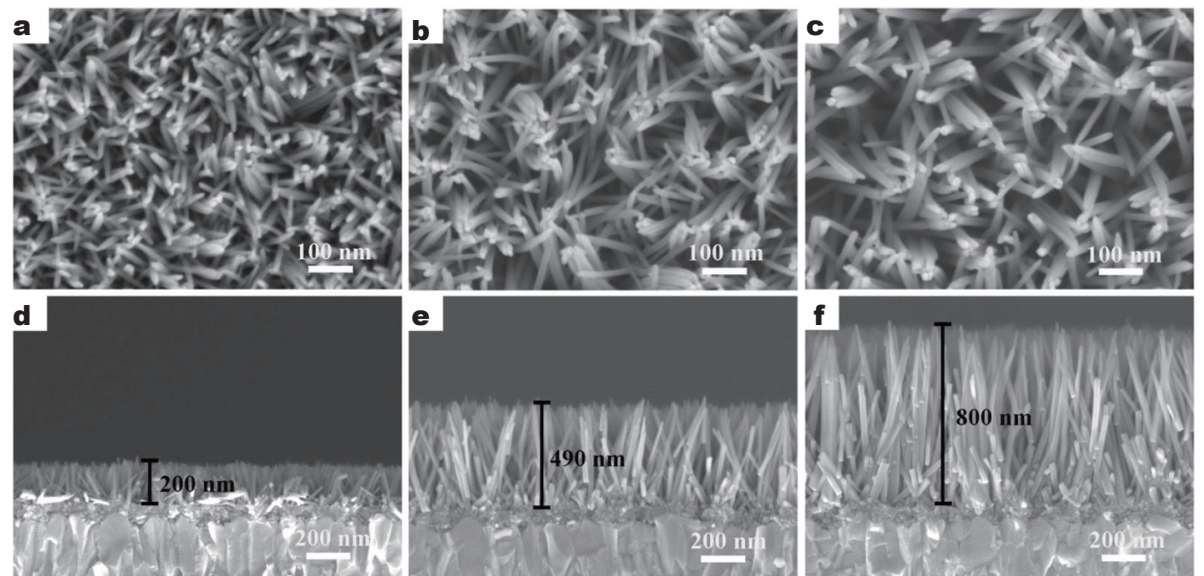

Figure 4 Surface and cross-sectional SEM images of $\mathrm{TiO}_{2}$ nanorod arrays with growth time of $75 \mathrm{~min}(\mathrm{a}, \mathrm{d}), 105 \mathrm{~min}$ (b, e), and $115 \mathrm{~min}$ (c, f). Reprinted with permission from Ref. [70], Copyright 2017, Elsevier.

hours, followed by drying and calcining, and a continuous series structure from nanotubes to nanowires can be synthesized just by adjusting the concentrations of TBT solutions from 0.1 to $2.0 \mathrm{~mol} \mathrm{~L}^{-1}$. $\mathrm{TiO}_{2}$ nanorod arrays with tunable diameters were prepared by Mirdamadi et al. [73]. The pressure by a syringe was used to increase the driving force, in order to fill the template pores. In a typical experiment, a $\mathrm{TiO}_{2}$ sol was prepared by dissolving titanium isoporpoxide (TTIP) in ethanol with a small amount of water. Then the sol was injected by a syringe into the AAM templates several times, and the samples were immediately immersed into boiling $\mathrm{TiO}_{2}$ sol for $20 \mathrm{~min}$. After being calcined at $400^{\circ} \mathrm{C}$ for $2 \mathrm{~h}$, the AAM templates were removed in $\mathrm{NaOH}$ solution. Therefore, combining the sol-gel method with template-based synthesis methods has been investigated to prepare $1 \mathrm{D} \mathrm{TiO}_{2}$ arrays.

On the base of an AAM template, $\mathrm{TiO}_{2}$ nanotube arrays can be prepared by electrochemical deposition [74]. Typically, the deposition process was carried out under potentiostatic conditions in $0.1 \mathrm{~mol} \mathrm{~L}^{-1} \mathrm{TiCl}_{3}$ aqueous solution, whose $\mathrm{pH}$ was maintained at 2.0 by adding $\mathrm{Na}_{2} \mathrm{CO}_{3}$ aqueous solution. After calcination processing and template removal, anatase $\mathrm{TiO}_{2}$ nanotube arrays were obtained. Similarly, $\mathrm{TiO}_{2}$ nanowires can also be obtained by this method.

Electrophoretic deposition is also an electrochemical method which has been widely explored in film deposition from colloidal dispersions [75]. It includes two steps, electrophoresis and precipitation. In the first step, an electric field is applied between two electrodes, the charged particles move toward the opposite electrode.
In the second step, the charged particles accumulate at the deposition electrode and form a relatively compact film. A combination of sol-gel method and electrophoretic deposition with AAM or PC templates has been used to synthesize $\mathrm{TiO}_{2}$ nanowires and nanorods [76]. In a typical experiment, $\mathrm{TiO}_{2}$ sol was formed by dissolving TTIP in acetic acid, followed by the addition of deionized water. Nanorod growth occured on a working electrode of aluminum. $\mathrm{TiO}_{2}$ sol was deposited into the pores of the PC membrane under a potential of $5 \mathrm{~V}$ for $1 \mathrm{~h}$. After calcining the $\mathrm{PC}$ membrane at $500^{\circ} \mathrm{C}$ for $1 \mathrm{~h}$, dense anatase $\mathrm{TiO}_{2}$ nanorods were obtained. $\mathrm{TiO}_{2}$ nanowires can also be prepared using an AAM template with long pores.

\section{Direct anodization of Ti metal}

Direct oxidation of Ti metal using anodization can be employed for the preparation of $1 \mathrm{D} \mathrm{TiO}_{2}$ nanotube arrays on $\mathrm{Ti}$ substrates. Anodization is an useful method for modifying surface structures to obtain nanoporous or nanotubular structures. Fabrication of $\mathrm{TiO}_{2}$ nanotubes via direct anodization of $\mathrm{Ti}$ foil in a $\mathrm{H}_{2} \mathrm{O}-\mathrm{HF}$ electrolyte was first reported by Grimes et al. [77]. Typically, a cleaned Ti foil was anodized in a $0.5 \% \mathrm{HF}$ solution under a direct current voltage of $20 \mathrm{~V}$ for $20 \mathrm{~min}$. The obtained nanotubes had an average tube diameter of approximately $60 \mathrm{~nm}$ and a tube length of only $250 \mathrm{~nm}$. The formation of nanotube arrays appears to be three simultaneously occurring processes: (1) field-assisted oxidation of $\mathrm{Ti}$ metal to form $\mathrm{TiO}_{2}$; (2) field-assisted dissolution of $\mathrm{Ti}$ metal ions in the electrolyte; and (3) chemical dissolution of $\mathrm{Ti}$ and $\mathrm{TiO}_{2}$ due to etching by fluoride ions [78]. 
Further studies concentrate mainly on precisely controlling the nanotube length, pore size, and wall thickness [79]. These parameters strongly depend on the electrolyte. Electrolyte composition and its $\mathrm{pH}$ determine the formation rate of both nanotube arrays and the resultant oxide dissolving. In most situations, $\mathrm{TiO}_{2}$ nanotube arrays are obtained by anodization in the existence of electrolyte containing fluoride ions.

\section{$\mathrm{TiO}_{2}$ NANOARRAYS/GRAPHENE COMPOSITES FOR WATER TREATMENT}

This part complements the earlier work [80] by extending to the application of $\mathrm{TiO}_{2}$ nanoarrays/graphene composite in water treatment. $\mathrm{TiO}_{2}$ nanoarrays or $\mathrm{TiO}_{2}$ nanoarrays/graphene composite coating on the substrate have unique properties in water treatment, owing to their fast electron transport and being easy to recycle after photocatalytic reaction. The combination of graphene with $\mathrm{TiO}_{2}$ nanoarrays limits the electron-hole recombination, extending the life time of the photoelectron hole pairs. Also, the formation of $\pi-\pi$ stacking between aromatic rings of graphene and organic pollutants also facilitates the adsorption of pollutants on the photocatalyst thereby enhancing the quenching of pollutants [81]. Therefore, the coupling of graphene with photoactive $\mathrm{TiO}_{2}$ greatly enhances the photocatalytic activity of $\mathrm{TiO}_{2}$ for the degradation of various waterborne pollutants such as pathogens, organic dyes and heavy metal ions. The unique properties of graphene, in combination with size-dependent properties of $\mathrm{TiO}_{2}$ nanoarray induce further functionalities for the composites such as extended light absorption range, high adsorption capacity and improved charge separation properties.

Especially, in recent years, algal blooms in sea and lake cause microcystins (MCs) which can cause acute and chronic toxicity to humans [2]. $\mathrm{TiO}_{2}$ nanoarrays or $\mathrm{TiO}_{2}$ nanoarrays/graphene composite coating on the substrate can not only kill the algal in the sea and lake to inhibit the reproduction of algal, but also decompose the MCs in the water, as shown in Fig. 5.

Compared with other substrates, flexible substrate has been considered as a good choice, because catalyst recovery can be solved by anchoring the $\mathrm{TiO}_{2}$ photocatalyst onto the substrate. Besides, these heterostructures with highly ordered nanoarrays on flexible substrates provide potential opportunities for flexible-device fabrication with optimal performance, such as photocatalysis devices and energy conversion/storage devices. Therefore, recycled $\mathrm{TiO}_{2}$ composite on the substrate is a very important advanced oxidation technology, playing an

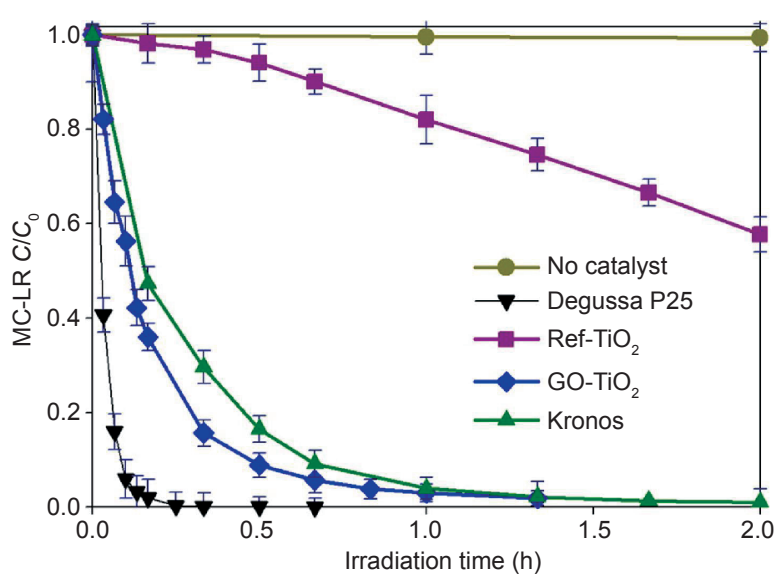

Figure 5 Photocatalytic degradation of $10 \mathrm{mg} \mathrm{L}^{-1}$ of MC-LR under solar light irradiation in the presence of different $\mathrm{TiO}_{2}$ based nanostructured materials, $200 \mathrm{mg} \mathrm{L}^{-1}$ (Degussa P25, Kronos, GO- $\mathrm{TiO}_{2}$, and ref- $-\mathrm{TiO}_{2}$ ), Degussa P25 and Kronos are used as standard materials for comparison. Reprinted with permission from Ref. [2], Copyright 2013, American Chemical Society.

important role in water treatment in the future.

\section{Antimicrobial treatment}

Recently, the research on antimicrobial activity of nanomaterials has gained great attention. Moreover, graphene has emerged as one of the most promising materials for application as antimicrobial materials [8285]. Other than the presence of organic pollutants and heavy metals in water, waterborne pathogens are also deleterious to human health, which need to be killed. For this, nanomaterials with antimicrobial activity can be employed for remediation and sterilization of water. Further coupling of graphene with $\mathrm{TiO}_{2}$ greatly enhances its antimicrobial activity, because $\mathrm{TiO}_{2}$ can contribute to the antimicrobial activity by producing active oxidative species which destructs the cell, and by increasing the surface area of graphene to promote the adherence of more cells to graphene (Fig. 6) [86]. Therefore, $\mathrm{TiO}_{2}$ nanoarrays/graphene composite exhibits excellent antimicrobial activity due to their synergistic effects.

$\mathrm{Xu}$ et al. [87] synthesized the filtration membranes by combining $\mathrm{TiO}_{2}$ with graphene. Despite of the encouraging findings, the application of the nanocomposite to kill bacteria in a recyclable and synergistic manner remains to be further explored. Recyclable antibacterial $\mathrm{TiO}_{2}$ nanoarrays/graphene composites are eco-friendly and low cost, because of reducing the usage of raw materials. It is observed that the lateral dimensions and morphology of the graphene oxide sheets play a key role in its efficacy 

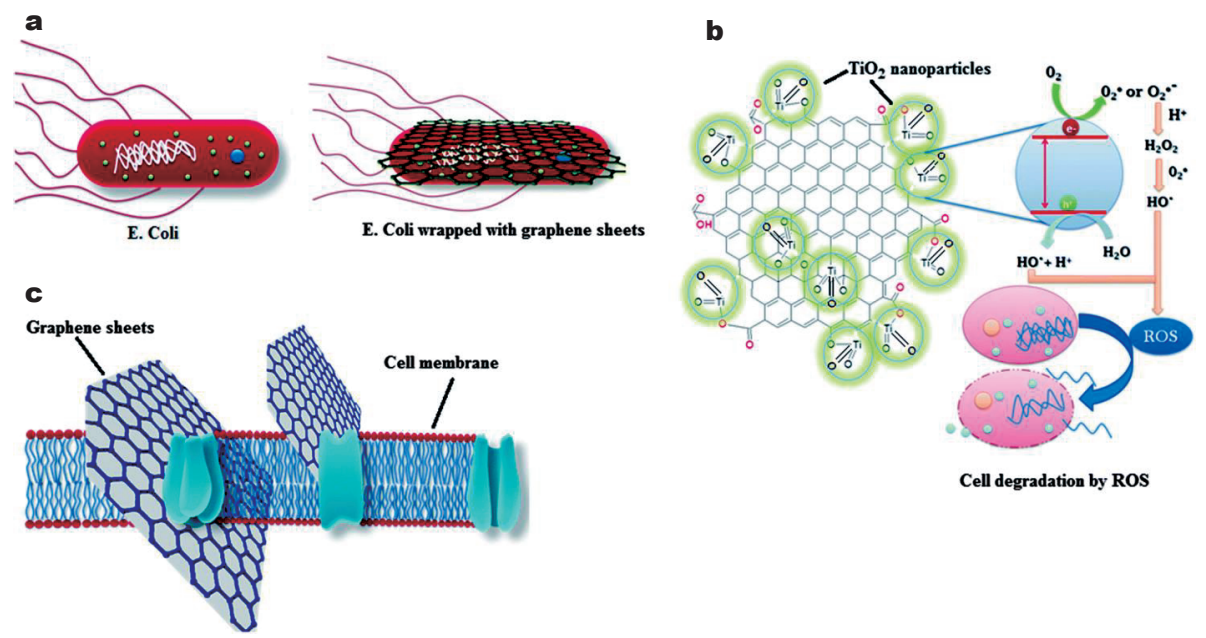

Figure 6 (a) Wrapping of E. coli by graphene sheets. (b) Slicing of cell membrane by sharp edges of graphene. (c) Mechanism involved in photoinactivation of cells by metal oxide/graphene composite. Reprinted with permission from Ref. [86], Copyright 2013, The Royal Society of Chemistry.

as antimicrobial agent [84]. Compared to the smaller sheets, the larger sheets exhibit higher antimicrobial activity. The reason is as follows: firstly, this complete wraping of bacterial cells by larger graphene sheets $\left(>0.4 \mu \mathrm{m}^{2}\right)$ could block all the available active sites, disallowing the cell proliferation. Secondly, smaller sized graphene oxide sheets $\left(<0.2 \mu \mathrm{m}^{2}\right)$ do stick to the cell membrane, which are not capable of occupying and isolating the whole cell surface, leading to low efficiency.

Ahmed et al. [40] investigated the effect of graphene oxide on wastewater borne microbial community. They found the fact that graphene oxide impaired the metabolic activity of microorganism, thereby restricting the cell proliferation and ultimately leading to the cell death. Reduced metabolic activity caused a reduction in the consumption of oxygen which would decrease the value of biological oxygen demand (BODs) [88]. The bacteria effectively interact with the graphene (oxide) nanosheets through direct contacting with such sharp edges. The cytoplasm of some bacteria leaks off thoroughly, indicating both outer and inner membrane damaged (Fig. 7). When bacteria directly contact with graphene, intensive physical interactions between graphene and bacterial cells may cause physical damages on cell membranes, leading to the release of intracellular contents [88]. This can be assigned to a stronger interaction between the more sharpened edges of graphene and the cell membrane of bacteria, or a better charge transfer between bacteria and the edge of graphene which finally result in further damage of the cell membrane of bacteria during the contact interaction.

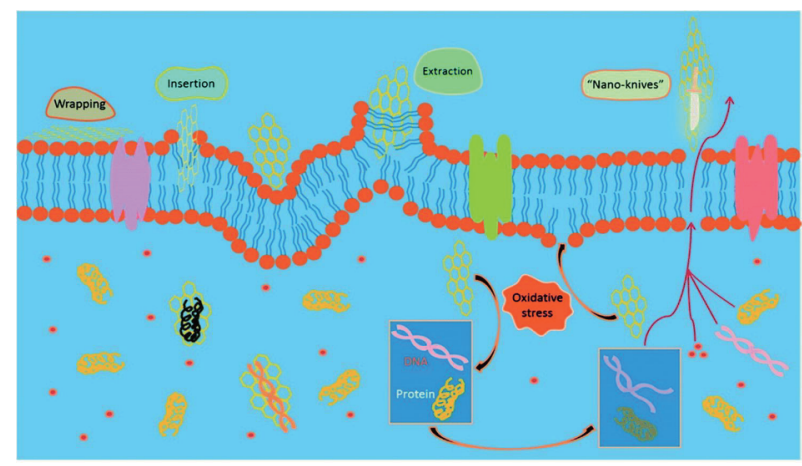

Figure 7 Mechanism of the antimicrobial activities of single-component graphene materials. Reprinted with permission from Ref. [88], Copyright 2017, The Royal Society of Chemistry.

Akhavan et al. [83] also contended that direct contact interaction of bacteria with the very sharp edge of graphene would result in much more damage to the cell membrane of Gram-positive S. aureus bacteria, which was lack of an outer membrane as compared to the Gram-negative E. coli ones.

The composites of graphene with $\mathrm{TiO}_{2}$ have also been explored as an antimicrobial agent for the sensitization and disinfection of water. Akhavan et al. [89] reported that graphene oxide $/ \mathrm{TiO}_{2}$ thin films annealed at $400^{\circ} \mathrm{C}$ could photo-inactivate E. coli $25 \%$ more efficiently, as compared to bare $\mathrm{TiO}_{2}$. In this case, graphene oxide served as an electron acceptor for the removal of electron from electron hole pair which generated by the exposure of photoactive material to light. Simultaneously, the quantum efficiency of the photocatalysis was enhanced by 
an increase in life time of the hole and a reduction in the electron-hole recombination. The graphene oxide/ $/ \mathrm{TiO}_{2}$ thin films exhibited significantly improved antibacterial activity by factors of 7.5, 3.7, 1.7 and 1.1, as compared to unsupported $\mathrm{TiO}_{2}, \mathrm{Ag}-\mathrm{SiO}_{2}, \mathrm{Ag}$ nanorods and $\mathrm{Ag}-\mathrm{TiO}_{2} /$ $\mathrm{Ag} / \mathrm{TiO}_{2}$ films [89].

The cytotoxicity of graphene/ $\mathrm{TiO}_{2}$ composite in miniscule nematodes was investigated by Thakur et al. [90]. Nearly $98.4 \%$ of the nematodes were inactivated, when exposed $\mathrm{TiO}_{2}$ /graphene composite whose ratio of surface area to volume $(S / V)$ is 10 , to the solar radiation within $4 \mathrm{~h}$. Cao et al. [23] reported that $\mathrm{TiO}_{2} /$ graphene composite with $4.2 \mathrm{wt} \%$ graphene showed photoactivity in visible spectrum as well, which was attributed to the formation of $\mathrm{Ti}-\mathrm{C}$ bond between $\mathrm{TiO}_{2}$ and graphene. The photocatalytic properties of $\mathrm{TiO}_{2}$ /graphene composite were tested against $E$. coli. It was observed that the composite showed excellent antibacterial activity and the bacterial cell viability was reduced to $9.5 \%$ after $12 \mathrm{~h}$ exposure in visible light.

It was further revealed that the major inactivation of nematodes was due to the interaction with reactive oxygen species (ROS) generated by the composite. Reactive oxygen species generated by $\mathrm{TiO}_{2}$ was also responsible for microbial cell inhibition, hindering the activity of ammonia by oxidizing bacteria and polyphosphate accumulating organisms, which were responsible for the removal of the following two nutrients: nitrogen (as $\mathrm{NH}_{3}-\mathrm{N}$ ) and phosphorous (as $\mathrm{PO}_{4}^{-}$) from waste water $[91,92]$. Also, the modification of the surface of graphene with molecules and functional groups, effectively prevented sheets folding and helped to maintain a stable dispersion. The presence of certain active groups such as $-\mathrm{COOH}$ and $-\mathrm{OH}$ can increase the surface roughness, which could thereby enhance the antimicrobial activity by damaging the outer membrane of cells via attrition and rubbing. Increasing the number of active groups on the surface of graphene effectively improves antimicrobial activity of graphene based composite. Sharp edges of graphene also contribute to its antimicrobial activity, wherein the atomically sharp edges can slice through the cell membrane [86].

One-dimensional nanomaterials such as nanorods, have also been utilized in combination with graphene oxide for photocatalytic degradation of microorganisms. Liu et al. [93] prepared $\mathrm{TiO}_{2}$ nanorod hybrids with graphene oxide and investigated their bactericidal activity by monitoring the effect of solar radiation exposure on the E. coli bacterial colony, in the presence of hybrid material. The $\mathrm{TiO}_{2}$ nanorods/graphene oxide composite showed significantly higher bacteriocidal activity as compared to the $\mathrm{TiO}_{2}$ nanoparticles/graphene oxide hybrid. $\mathrm{TiO}_{2}$ nanorods/graphene oxide composite inactivated $90 \%$ E. coli within $27 \mathrm{~min}$, but $\mathrm{TiO}_{2}$ nanoparticles/graphene oxide hybrid took $52 \mathrm{~min}$ to achieve same performance. Therefore, specific structures and morphologies are very important because they could provide a high degree of edge planes.

To some extent, graphene coated on $\mathrm{TiO}_{2}$ nanoarrays may reduce the light absorption, which is the potential drawbacks. But on the basis of the above advantages of $\mathrm{TiO}_{2}$ nanoarrays/graphene and the suitable composite structure, the influence of the reduced light absorption by graphene itself on photocatalytic reaction is weak. Moreover, graphene coated on $\mathrm{TiO}_{2}$ nanoarrays greatly improves the adsorptive and antimicrobial activities in water treatment. Therefore, $\mathrm{TiO}_{2}$ nanoarrays coupling with graphene have greatly enhanced the photocatalytic properties and antimicrobial efficiency in water treatment.

\section{Adsorption}

Adsorption is one of the most important phenomena for desalination of water. As compared to other water treatment, the advanced water treatment technology with $\mathrm{TiO}_{2}$ nanoarrays/graphene composites can remove nearly all types of pollutants from waste water, offering several advantages such as ease of recycling, and no harmful generation of by-products during the treatment [94]. As the metal ions cannot be degraded by photocatalysis or any other chemical reaction, adsorption is a preferred approach due to its effective removal of toxic heavy metal ions. More importantly, graphene exhibits a much higher surface area than activated carbon, and thus can act as an efficient adsorbent. In addition to unprecedented surface area, graphene derivative also provides functionalities which can favour selective adsorption of pollutants [95]. Graphene oxide is highly acidic in nature, therefore it can readily adsorb basic molecules and cations. Moreover, when graphene is modified with surfactant, the presence of active groups such as carbonyl, epoxy and hydroxyl groups on the surface of graphene oxide enables it to interact with a wide variety of molecules [96]. Until now, graphene has been explored as an adsorbent for the removal of various dyes, heavy metal ions [97] and other aromatic pollutants [98].

Recently, numerous studies were devoted to utilization of self-assembled $\mathrm{TiO}_{2}$ on graphene or reduced graphene oxide for removal of different water pollutants. The incorporation of $\mathrm{TiO}_{2}$ nanoarrays on graphene can 
reduce their restacking and aggregation, thereby enhancing the surface area of the composite $[99,100]$. At the same time, in situ growth of $\mathrm{TiO}_{2}$ nanoarrays on graphene results in less agglomeration. Furthermore, the functional groups and defect sites of graphene can act as the nucleation and growth sites for $\mathrm{TiO}_{2}$. The combination of graphene with $\mathrm{TiO}_{2}$ nanoarrays extends the life time of the adsorbent material by acting as support material, which inhibits leaching of fine $\mathrm{TiO}_{2}$ into treated water.

As a hot issue, photocatalysis has witnessed an enormous change over the past two decades, which makes significant advancements in the preparation of novel form nanomaterials and the design of efficient photodegradation processes in water treatment. Thus, the development of a simple recyclable photocatalyst not only prevent the excessive use of photocatalysts, but also contribute to the recovery of photocatalysts, which is green and benefit to water environment. Therefore, one of the great challenges of photocatalyst study is to devise recycled new catalysts that exhibit high activity under illumination by visible light.

\section{$\mathrm{TiO}_{2}$ NANOARRAY/GRAPHENE COMPOSITES FOR ENERGY CONVERSION/STORAGE}

\section{Solar cell}

Over the last decades, $\mathrm{TiO}_{2}$ nanoarrays have been widely applied as one of the efficient charge separation and electron transporting materials in the fields of dye sensitized solar cells (DSSC) [65,101], quantum dot sensitized solar cells [102], and organolead halide perovskite solar cells [103]. As one of the important components of solar cells, the $\mathrm{TiO}_{2}$ photoanode has a great effect on light conversion efficiency. The length, diameter, surface hydroxyl group content and areal density of $\mathrm{TiO}_{2}$ nanoarrays strongly affect the interface charge separation and photovoltaic performance of the corresponding solar cells. The $\mathrm{TiO}_{2}$ nanoarrays/graphene composite with unique properties have been used in photovoltaic studies, in which highly ordered nanoarray structure accelerates electron transport and ordered surface increases sensitizer absorption [70,104].

Clearly, oriented single-crystal $\mathrm{TiO}_{2}$ nanowires or nanorods on FTO glass would be most suitable for fast electron transport [30,105]. Moreover, among these preparation techniques, growing the $1 \mathrm{D} \mathrm{TiO}_{2}$ nanorods/ wires directly on FTO glass by hydrothermal/solvothermal method is the most promising technique due to its
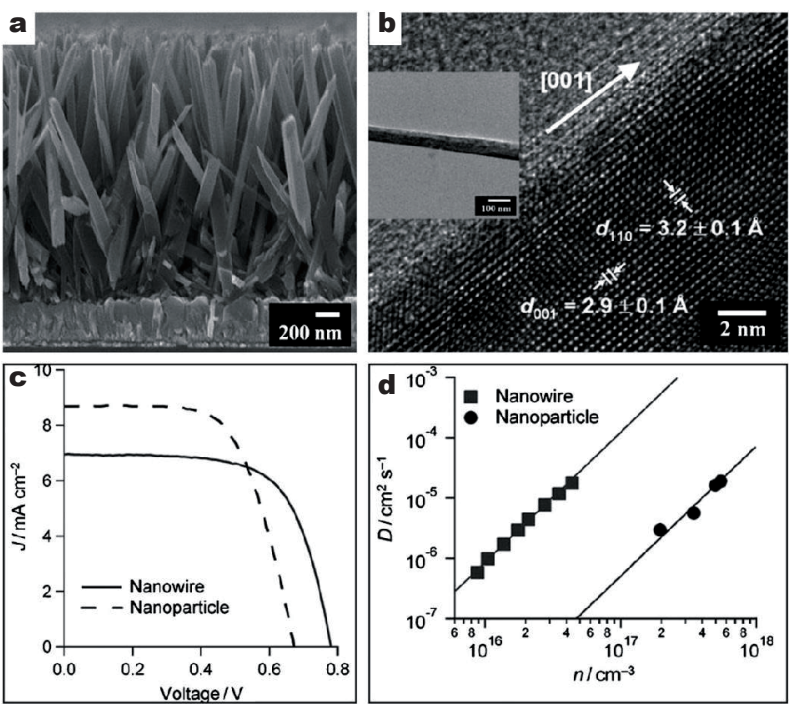

Figure 8 DSSCs with $\mathrm{TiO}_{2}$ nanorod arrays. (a) Field emission SEM (FESEM) cross-sectional image of rutile $\mathrm{TiO}_{2}$ nanorod arrays grown on an FTO substrate, (b) high-resolution transmission electron microscopy (HR-TEM) image of a single nanorod array shown in the inset. (c) $J-V$ characteristics of DSSCs based on a $4.5 \mu \mathrm{m}$ long rutile $\mathrm{TiO}_{2}$ nanowire arrays and a rutile $\mathrm{TiO}_{2}$ nanoparticle film, (d) comparison of electron diffusion coefficients $(D)$ as a function of the photoelectron density $(n)$ for rutile nanowire- and nanoparticle-based DSSCs with a laser illumination at $680 \mathrm{~nm}$. Reprinted with permission from Ref. [30,65,106], Copyright 2014, Elsevier.

simplicity and low cost. As shown in Fig. 8, nanorods with $\sim 90 \mathrm{~nm}$ in diameter and $1.9 \mu \mathrm{m}$ in length were formed at $150^{\circ} \mathrm{C}$ for $20 \mathrm{~h}$ [65]. These nanorods were polycrystalline rutile and grew along the [001] direction with the growth axis parallel to the substrate surface normal (Fig. 8a, b). The photoelectric conversion efficiency (PCEs) were almost the same $(3.68 \%$ for nanowires and $3.74 \%$ for nanoparticles), while the short-circuit current values $\left(J_{\text {sc }}\right)$ were distinct $\left(6.95 \mathrm{~mA} \mathrm{~cm}^{-2}\right.$ for nanowires and $8.70 \mathrm{~mA} \mathrm{~cm}^{-2}$ for nanoparticles). The $20 \%$ lower $J_{\text {sc }}$ value for nanowirebased DSSCs primarily resulted from their lower surface area than the nanoparticle-based cell. Shi et al. [70] successfully prepared a $\mathrm{TiO}_{2}$ nanorod array with a length of $200 \mathrm{~nm}$, a diameter of $13 \mathrm{~nm}$ and an areal density of $1,100 \mathrm{~mm}^{-2}$ using a hydrothermal method, as shown in Fig. 9. It showed that the structure of nanorod array was beneficial to the infiltration of ion and hole transport in the solar cell. Feng et al. [105] prepared the rutile $\mathrm{TiO}_{2}$ nanowire arrays with the length of 900,600 and $400 \mathrm{~nm}$. And they found that the corresponding performance of perovskite solar cells gave the PCEs of $11.7 \%, 10.8 \%$, and $9.7 \%$, respectively. This is a good evidence that the 1D nanostructures may offer better charge transport than 

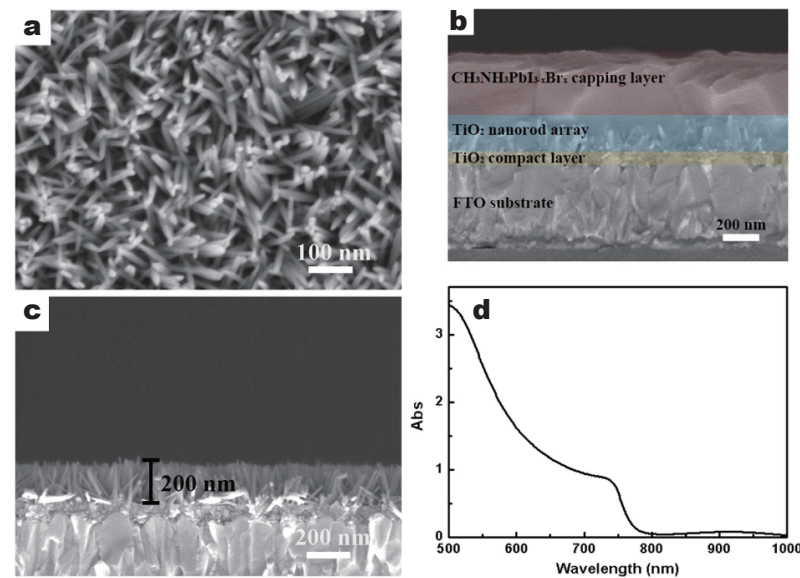

Figure 9 Surface (a) and cross-sectional (c) of $\mathrm{TiO}_{2}$ nanorod array, cross-sectional (b) and UV-Vis-NIR spectrum (d) of $\mathrm{CH}_{3} \mathrm{NH}_{3} \mathrm{PbI}_{3-x} \mathrm{Br}_{x}$ thin film based on the $\mathrm{TiO}_{2}$ nanorod array. Reprinted with permission from Ref. [70], Copyright 2017, Elsevier.

nanoparticles. Further increment in PCEs of 1D nanostructures most likely depends on the enhancement of surface area.

However, ordered $\mathrm{TiO}_{2}$ nanorods/wires arrays also suffer from the drawbacks such as high electron-hole pair recombination which leads to low charge density in the photoanode. Considering this fact, hybridization of graphene and $\mathrm{TiO}_{2}$ nanoarrays could enhance the photoanode activity by increasing electron mobility and reducing the recombination of the electron and hole. Lee et al. [40] reported that graphene/ $\mathrm{TiO}_{2}$ photoelectrodes could display enhanced dye adsorption properties with lower internal resistances and faster transport time. The maximum power conversion efficiency of DSSCs was 9.32\% with optimized DSSC parameters, which represented that the addition of GR would increase dye loading and enhance DSSC efficiency. Wang et al. [99] showed that printing $\mathrm{TiO}_{2}$ /graphene nanocrystals on $\mathrm{TiO}_{2}$ nanoarrays to prepare the photoanode of solar cells could achieve the increased absorbability for dye and the increased absorption of visible light, and enhanced efficiency of the cell by $35 \%$, compared with the $\mathrm{TiO}_{2} /$ graphene nanocrystals film. This transparent graphene/ $\mathrm{TiO}_{2}$ nanoarray photoanode exhibited a high conversion of light to electricity.

\section{Energy storage}

Recently, our group have tried to use various morphologies of nanomaterials as the electrodes to enhance the electrochemical performance, in order to achieve the high power and energy density of electrochemical energy storage devices [107-110]. Among them, well-defined 1D hetero-nanostructures combine the advantages and overcome the limitations of different electrochemically active materials. Mai et al. [111] reported that $\mathrm{V}_{2} \mathrm{O}_{5}$ nanowires/ graphene (VOG) was synthesized using a liquid phase method. The highly interconnected vanadium oxide nanowires framework was supported by reduced grapheme oxide. The cycling performance of VOG indicated that a $71 \%$ of the maximum capacity was achieved after 900 cycles. The initial increase in capacity for the first 50 cycles might be attributed to the activation of bilayer $\mathrm{V}_{2} \mathrm{O}_{5}$ at a high current density of $6 \mathrm{~A} \mathrm{~g}^{-1}$. An et al. [112] synthesized nanowires/GO nanocomposites via freeze drying and annealing process. This $\mathrm{V}_{2} \mathrm{O}_{5} / \mathrm{GO}$ aerogel exhibited excellent electrochemical performance in $\mathrm{Mg}^{2+}$ ions storage. Except the special structure that graphene was convolved by $\mathrm{V}_{2} \mathrm{O}_{5}$ nanowires, the crystal water molecules in layers also played an important role in $\mathrm{Mg}^{2+}$ ions diffusion.

$\mathrm{TiO}_{2}$ has received much attention for Li-ion battery because of its several merits such as low cost and friendly environment. Importantly, $\mathrm{TiO}_{2}$ is a quick and low voltage insertion host for $\mathrm{Li}$, and its structure can keep stable during the $\mathrm{Li}$ insertion extraction process [113]. However, just like every coin has two sides, $\mathrm{TiO}_{2}$ also has its weaknesses, for example poor cycling performance due to its poor electron transport ability. Therefore, lots of efforts have been made to overcome these disadvantages. Kim et al. [114] reported a hybrid supercapacitor combining the advantages of Li-ion batteries and supercapacitors based on anatase $\mathrm{TiO}_{2}$-rGO (Fig. 10a). Fig. 10b clearly showed that the hybrid supercapacitor could deliver far higher power and energy densities. As an energy storage device as popular as batteries, supercapacitor can provide high power density because of fast surface reactions. However, general supercapacitors suffer from low energy density as a result of limited surface charge storage.

Therein, $\mathrm{TiO}_{2}$ nanoarrays not only shorten the ion diffusion length, but also reduce the ionic diffusion resistance and charge transfer resistance. To make the structure more innovative, Ramadoss et al. [115] prepared $\mathrm{rGO} / \mathrm{TiO}_{2}$ nanorod/rGO sandwich electrode and confirmed the specific capacitance retention ratio was $85 \%$ even after 4,000 cycles (Fig. 10d, e). In this electrode, rGO nanosheets acted as an interconnector to improve the internal electrical conductivity and cyclability. In addition, the enhanced specific surface area of the electrode greatly improved the charge capacity. Simultaneously, the $\mathrm{TiO}_{2}$ nanorod arrays acted as infrastructure 


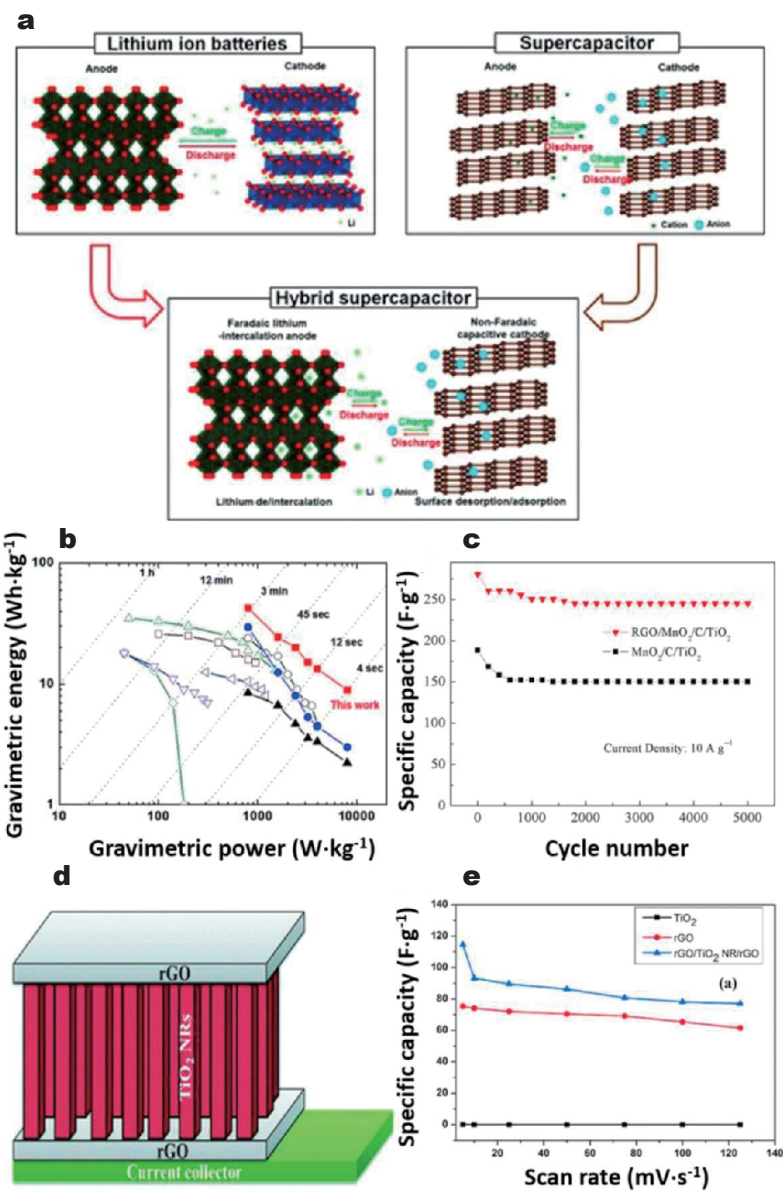

Figure 10 (a) Illustration of a typical hybrid supercapacitor. The hybrid supercapacitor uses a non-Faradaic capacitive cathode like those used in supercapacitors and a Faradaic lithium intercalation anode like those used in Li-ion batteries. (b) Ragone plots of various hybrid supercapacitors, (c) Cycle performance of the $\mathrm{RGO} / \mathrm{MnO}_{2} / \mathrm{C} / \mathrm{TiO}_{2}$ and $\mathrm{MnO}_{2} /$ $\mathrm{C} / \mathrm{TiO}_{2}$ electrode at a current density of $10 \mathrm{~A} \mathrm{~g}^{-1}$. (d) Schematic diagram of an $\mathrm{rGO} / \mathrm{TiO}_{2}$ nanorod/rGO electrode. (e) Specific capacitance of $\mathrm{TiO}_{2}$ nanorods, $\mathrm{rGO}$ and an $\mathrm{rGO} / \mathrm{TiO}_{2}$ nanorod/rGO electrode at various scan rates. Reprinted with permission from Ref. [116], Copyright 2017, Elsevier.

bridging the GR nanosheets, preventing them from serious swelling during the cycling process. These results suggested that the tested cell could exhibit superior performance in $\mathrm{TiO}_{2}$ nanoarrays/graphene supercapacitors with aqueous electrolyte.

\section{CONCLUSION AND OUTLOOK}

This review focuses on $\mathrm{TiO}_{2}$ nanoarrays and $\mathrm{TiO}_{2}$ nanoarrays/graphene composite as photocatalysis and photoanode with their practical use in water treatment and energy conversion/storage. The foremost goal on photovoltaic materials is to explore the light harvesting, limit the electron-hole pairs recombination and electron losses. Owing to its excellent physical and chemical properties, $\mathrm{TiO}_{2}$ nanoarrays/graphene is undoubtedly suitable to act as the perfect material for photocatalysis and energy conversion/storage. According to the literature reviews, their conversion efficiency based on $\mathrm{TiO}_{2}$ nanoarrays and $\mathrm{TiO}_{2}$ nanoarrays/graphene are promising as compared to the pure $\mathrm{TiO}_{2}$ and graphene. Some have ascribed the excellent catalytic activities to better accessibility of reacting molecules into $\mathrm{TiO}_{2}$ nanoarrays. And some papers assume that the intimate interaction between $\mathrm{TiO}_{2}$ and graphene leads to efficient electron transfer. This article presents a comprehensive review on the application and mechanism of $\mathrm{TiO}_{2}$ nanoarrays or $\mathrm{TiO}_{2}$ nanoarrays/graphene composites in water treatment and their role as photocatalyst, antimicrobial activities and adsorbent in water remediation. Through this review, we discuss the current state of $\mathrm{TiO}_{2}$ nanoarrays/graphene composite for water purification and also provide a comprehensive analysis of these composites about their photocatalytic, adsorptive and antimicrobial activities on various types of pollutants. Also, due to its excellent electrical and thermal conductivity, mechanical strength and high surface area, $\mathrm{TiO}_{2}$ nanoarrays/graphene composite on the substrate is an ideal photoanode applied in energy conversion/ storage.

A brief perspective on the challenges and new directions in the area is also provided for researchers interested in designing advanced photochemical materials for water treatment and energy conversion/storage. Anchoring $\mathrm{TiO}_{2}$ nanoarrays/graphene on the substrate (especially flexible substrate) has been considered as a good choice because of easy recovery of the photocatalyst in water treatment, which is friendly to environment. Besides, $\mathrm{TiO}_{2}$ nanoarrays/graphene on flexible substrates could provide potential opportunities for flexible-device fabrication with optimal performance in energy conversion/storage devices.

Received 26 July 2018; accepted 28 August 2018; published online 16 October 2018

1 Chen J, Qiu F, Xu W, et al. Recent progress in enhancing photocatalytic efficiency of $\mathrm{TiO}_{2}$-based materials. Appl Catal AGeneral, 2015, 495: 131-140

2 Fotiou T, Triantis TM, Kaloudis T, et al. Photocatalytic degradation of microcystin-LR and off-odor compounds in water under UV-A and solar light with a nanostructured photocatalyst based on reduced graphene oxide- $\mathrm{TiO}_{2}$ composite. identification of intermediate products. Ind Eng Chem Res, 2013, 52: 13991- 
14000

3 Tahir MS, Saleem M, Malik SR, et al. An innovative and advanced oxidation process for effluent treatment through wet tube-type electrostatic precipitation. Chem Eng Proc-Proc Intensif, 2012, 52: $16-20$

4 de Mello Ferreira A, Marchesiello M, Thivel PX. Removal of copper, zinc and nickel present in natural water containing $\mathrm{Ca}^{2+}$ and ions by electrocoagulation. Sep Purif Tech, 2013, 107: 109117

5 Centi G, Perathoner S, Torre T, et al. Catalytic wet oxidation with $\mathrm{H}_{2} \mathrm{O}_{2}$ of carboxylic acids on homogeneous and heterogeneous Fenton-type catalysts. Catal Today, 2000, 55: 61-69

6 Ghosh P, Samanta AN, Ray S. Reduction of COD and removal of $\mathrm{Zn}^{2+}$ from rayon industry wastewater by combined electro-Fenton treatment and chemical precipitation. Desalination, 2011, 266: $213-217$

7 Ayodele OB, Hameed BH. Synthesis of copper pillared bentonite ferrioxalate catalyst for degradation of 4-nitrophenol in visible light assisted Fenton process. J Ind Eng Chem, 2013, 19: 966-974

8 Lee SY, Park $\mathrm{SJ} \mathrm{TiO}_{2}$ photocatalyst for water treatment applications. J Industrial Eng Chem, 2013, 19: 1761-1769

9 Yu H, Chen S, Quan X, Zhang Z. The mechanism. materials and reactors of photocatalytic disinfection in water and wastewater treatment. Prog Chem, 2017, 29(9): 1030-1041

10 Wu WQ, Feng HL, Chen HY, et al. Recent advances in hierarchical three-dimensional titanium dioxide nanotree arrays for high-performance solar cells. J Mater Chem A, 2017, 5: 1269912717

11 Zhou L, Zhang $\mathrm{K}, \mathrm{Hu} \mathrm{Z}$, et al. Recent developments on and prospects for electrode materials with hierarchical structures for lithium-ion batteries. Adv Energy Mater, 2018, 8: 1701415

12 Kumar SG, Devi LG. Review on modified $\mathrm{TiO}_{2}$ photocatalysis under UV/visible light: selected results and related mechanisms on interfacial charge carrier transfer dynamics. J Phys Chem A, 2011, 115: 13211-13241

13 Inoue T, Fujishima A, Konishi S, et al. Photoelectrocatalytic reduction of carbon dioxide in aqueous suspensions of semiconductor powders. Nature, 1979, 277: 637-638

14 Park H, Park Y, Kim W, et al. Surface modification of $\mathrm{TiO}_{2}$ photocatalyst for environmental applications. J PhotoChem PhotoBiol C-PhotoChem Rev, 2013, 15: 1-20

15 Liu X, Zhao X, Zhu Y, et al. Experimental and theoretical investigation into the elimination of organic pollutants from solution by layered double hydroxides. Appl Catal B-Environ, 2013, 140-141: 241-248

16 Huang $\mathrm{H}$, Lim CK, Tse MS, et al. $\mathrm{SnO}_{2}$ nanorod arrays: low temperature growth, surface modification and field emission properties. Nanoscale, 2012, 4: 1491-1496

17 Kalanur SS, Hwang YJ, Chae SY, et al. Facile growth of aligned $\mathrm{WO}_{3}$ nanorods on FTO substrate for enhanced photoanodic water oxidation activity. J Mater Chem A, 2013, 1: 3479-3488

18 Kang JH, Myung $\mathrm{Y}$, Choi JW, et al. $\mathrm{Nb}_{2} \mathrm{O}_{5}$ nanowire photoanode sensitized by a composition-tuned $\mathrm{CdS}_{x} \mathrm{Se}_{1-x}$ shell. J Mater Chem, 2012, 22: 8413-8419

19 Wang J, Du N, Zhang $\mathrm{H}$, et al. Large-scale synthesis of $\mathrm{SnO}_{2}$ nanotube arrays as high-performance anode materials of Li-Ion batteries. J Phys Chem C, 2011, 115: 11302-11305

20 Yang $\mathrm{P}$, Wang K, Liang Z, et al. Enhanced wettability performance of ultrathin $\mathrm{ZnO}$ nanotubes by coupling morphology and size effects. Nanoscale, 2012, 4: 5755-5760
21 Singh P, Mondal K, Sharma A. Reusable electrospun mesoporous $\mathrm{ZnO}$ nanofiber mats for photocatalytic degradation of polycyclic aromatic hydrocarbon dyes in wastewater. J Colloid Interface Sci, 2013, 394: 208-215

22 Wang Y, Zhang HJ, Lim WX, et al. Designed strategy to fabricate a patterned $\mathrm{V}_{2} \mathrm{O}_{5}$ nanobelt array as a superior electrode for Li-ion batteries. J Mater Chem, 2011, 21: 2362-2368

23 Wei Q, Xiong F, Tan S, et al. Porous one-dimensional nanomaterials: design, fabrication and applications in electrochemical energy storage. Adv Mater, 2017, 29: 1602300

24 Zhong $\mathrm{P}$, Chen $\mathrm{X}, \mathrm{Xi} \mathrm{H}$, et al. Freeze drying as a novel approach to improve charge transport in titanium dioxide nanorod arrays. ChemElectroChem, 2017, 4: 2783-2787

25 Zhou W, Liu H, Boughton RI, et al. One-dimensional singlecrystalline $\mathrm{Ti}-\mathrm{O}$ based nanostructures: properties, synthesis, modifications and applications. J Mater Chem, 2010, 20: 5993

26 Joshi RK, Schneider JJ. Assembly of one dimensional inorganic nanostructures into functional 2D and 3D architectures. Synthesis, arrangement and functionality. Chem Soc Rev, 2012, 41: 5285

27 Zhang Q, Yodyingyong S, Xi J, et al. Oxidenanowires for solar cell applications. Nanoscale, 2012, 4: 1436-1445

28 Cai J, Ye J, Chen S, et al. Self-cleaning, broadband and quasiomnidirectional antireflective structures based on mesocrystalline rutile $\mathrm{TiO}_{2}$ nanorod arrays. Energy Environ Sci, 2012, 5: 75757581

29 Hochbaum AI, Yang P. Semiconductor nanowires for energy conversion. Chem Rev, 2010, 110: 527-546

30 Wang H, Guo Z, Wang S, et al. One-dimensional titania nanostructures: Synthesis and applications in dye-sensitized solar cells. Thin Solid Films, 2014, 558: 1-19

$31 \mathrm{Yu}$ L, Ruan S, Xu X, et al. One-dimensional nanomaterial-assembled macroscopic membranes for water treatment. Nano Today, 2017, 17: 79-95

32 Yang G, Jiang Z, Shi H, et al. Preparation of highly visible-light active N-doped $\mathrm{TiO}_{2}$ photocatalyst. J Mater Chem, 2010, 20: 5301-5309

33 Ryu J, Choi W. Substrate-specific photocatalytic activities of $\mathrm{TiO}_{2}$ and multiactivity test for water treatment application. Environ Sci Technol, 2008, 42: 294-300

34 Martyanov IN, Uma S, Rodrigues S, et al. Structural defects cause $\mathrm{TiO}_{2}$-based photocatalysts to be active in visible light. Chem Commun, 2004, 21: 2476

35 Etacheri V, Seery MK, Hinder SJ, et al. Oxygen rich titania: a dopant free, high temperature stable, and visible-light active anatase photocatalyst. Adv Funct Mater, 2011, 21: 3744-3752

36 Li K, Chen T, Yan L, et al. Design of graphene and silica co-doped titania composites with ordered mesostructure and their simulated sunlight photocatalytic performance towards atrazine degradation. Colloids Surfs A-Physicochem Eng Aspects, 2013, 422: 90-99

37 Jiang $\mathrm{T}$, Zhang L, Ji M, et al. Carbon nanotubes/ $/ \mathrm{TiO}_{2}$ nanotubes composite photocatalysts for efficient degradation of methyl orange dye. Particuology, 2013, 11: 737-742

38 Woan K, Pyrgiotakis G, Sigmund W. Photocatalytic carbon-nanotube- $\mathrm{TiO}_{2}$ composites. Adv Mater, 2009, 21: 2233-2239

39 Novoselov KS, Geim AK, Morozov SV, et al. Electric field effect in atomically thin carbon films. Science, 2004, 306: 666-669

40 Low FW, Lai CW. Recent developments of graphene- $\mathrm{TiO}_{2}$ composite nanomaterials as efficient photoelectrodes in dye-sensitized 
solar cells: A review. Renew Sustain Energy Rev, 2018, 82: 103125

41 Karaolia P, Michael-Kordatou I, Hapeshi E, et al. Removal of antibiotics, antibiotic-resistant bacteria and their associated genes by graphene-based $\mathrm{TiO}_{2}$ composite photocatalysts under solar radiation in urban wastewaters. Appl Catal B-Environ, 2018, 224: 810-824

42 Ye $\mathrm{T}$, Chen $\mathrm{W}, \mathrm{Xu} \mathrm{H}$, et al. Preparation of $\mathrm{TiO}_{2}$ /graphene composite with appropriate $\mathrm{N}$-doping ratio for humic acid removal. J Mater Sci, 2018, 53: 613-625

43 Formo E, Lee E, Campbell D, et al. Functionalization of electrospun $\mathrm{TiO}_{2}$ nanofibers with Pt nanoparticles and nanowires for catalytic applications. Nano Lett, 2008, 8: 668-672

$44 \mathrm{Yu} \mathrm{H}$, Irie H, Shimodaira $\mathrm{Y}$, et al. An efficient visible-light-sensitive $\mathrm{Fe}(\mathrm{III})$-grafted $\mathrm{TiO}_{2}$ photocatalyst. J Phys Chem C, 2010, 114: 16481-16487

45 Ali Z, Aslam M, Ismail IMI, et al. Synthesis, characterization and photocatalytic activity of $\mathrm{Al}_{2} \mathrm{O}_{3}-\mathrm{TiO}_{2}$ based composites. J Environ Sci Health Part A, 2014, 49: 125-134

46 Duan M, Li J, Mele G, et al. Photocatalytic activity of novel tin porphyrin/ $\mathrm{TiO}_{2}$ based composites. J Phys Chem C, 2010, 114: 7857-7862

47 Zhang $\mathrm{P}$, Zhang $\mathrm{X}$, Zhang $\mathrm{S}$, et al. One-pot green synthesis, characterizations, and biosensor application of self-assembled reduced graphene oxide-gold nanoparticle hybrid membranes. J Mater Chem B, 2013, 1: 6525-6531

48 Wang J, Ouyang Z, Ren Z, et al. Self-assembled peptide nanofibers on graphene oxide as a novel nanohybrid for biomimetic mineralization of hydroxyapatite. Carbon, 2015, 89: 20-30

49 Zhang $\mathrm{H}, \mathrm{Xu}$ P, Du G, et al. A facile one-step synthesis of $\mathrm{TiO}_{2} /$ graphene composites for photodegradation of methyl orange. Nano Res, 2011, 4: 274-283

50 Zhang N, Zhang Y, Xu YJ. Recent progress on graphene-based photocatalysts: current status and future perspectives. Nanoscale, 2012, 4: 5792

51 Wang W, Yu J, Xiang Q, et al. Enhanced photocatalytic activity of hierarchical macro/mesoporous $\mathrm{TiO}_{2}$-graphene composites for photodegradation of acetone in air. Appl Catal B-Environ, 2012, 119-120: 109-116

52 Bukowski B, Deskins NA. The interactions between $\mathrm{TiO}_{2}$ and graphene with surface inhomogeneity determined using density functional theory. Phys Chem Chem Phys, 2015, 17: 29734-29746

53 Luo Y, Heng Y, Dai X, et al. Preparation and photocatalytic ability of highly defective carbon nanotubes. J Solid State Chem, 2009, 182: 2521-2525

54 Xiang Q, Yu J, Jaroniec M. Graphene-based semiconductor photocatalysts. Chem Soc Rev, 2012, 41: 782-796

55 Shiraishi Y, Shiota S, Hirakawa H, et al. Titanium dioxide/reduced graphene oxide hybrid photocatalysts for efficient and selective partial oxidation of cyclohexane. ACS Catal, 2017, 7: 293-300

56 Cheng $\mathrm{P}$, Yang Z, Wang $\mathrm{H}$, et al. $\mathrm{TiO}_{2}$-graphene nanocomposites for photocatalytic hydrogen production from splitting water. Int $\mathrm{J}$ Hydrogen Energy, 2012, 37: 2224-2230

57 Yu H, Xiao P, Tian J, et al. Phenylamine-functionalized $\mathrm{rGO} / \mathrm{TiO}_{2}$ photocatalysts: spatially separated adsorption sites and tunable photocatalytic selectivity. ACS Appl Mater Interfaces, 2016, 8: 29470-29477

58 Wang CW, Chen JB, Wang LQ, et al. Single crystal $\mathrm{TiO}_{2}$ nanorods: Large-scale synthesis and field emission. Thin Solid
Films, 2012, 520: 5036-5041

59 Miao Z, Xu D, Ouyang J, et al. Electrochemically induced sol-gel preparation of single-crystalline $\mathrm{TiO}_{2}$ nanowires. Nano Lett, 2002, 2: 717-720

60 Dong S, Wang H, Gu L, et al. Rutile $\mathrm{TiO}_{2}$ nanorod arrays directly grown on $\mathrm{Ti}$ foil substrates towards lithium-ion micro-batteries. Thin Solid Films, 2011, 519: 5978-5982

61 Iraj M, Nayeri FD, Asl-Soleimani E, et al. Controlled growth of vertically aligned $\mathrm{TiO}_{2}$ nanorod arrays using the improved hydrothermal method and their application to dye-sensitized solar cells. J Alloys Compd, 2016, 659: 44-50

$62 \mathrm{Xu} \mathrm{Z}$, Yin $\mathrm{M}$, Sun J, et al. 3D periodic multiscale $\mathrm{TiO}_{2}$ architecture: a platform decorated with graphene quantum dots for enhanced photoelectrochemical water splitting. Nanotechnology, 2016, 27: 115401

63 Patel SKS, Gajbhiye NS, Date SK. Ferromagnetism of Mn-doped $\mathrm{TiO}_{2}$ nanorods synthesized by hydrothermal method. J Alloys Compd, 2011, 509: S427-S430

$64 \mathrm{Lv} \mathrm{M}$, Zheng $\mathrm{D}$, Ye $\mathrm{M}$, et al. Densely aligned rutile $\mathrm{TiO}_{2}$ nanorod arrays with high surface area for efficient dye-sensitized solar cells. Nanoscale, 2012, 4: 5872-5879

65 Liu B, Aydil ES. Growth of oriented single-crystalline rutile $\mathrm{TiO}_{2}$ nanorods on transparent conducting substrates for dye-sensitized solar cells. J Am Chem Soc, 2009, 131: 3985-3990

66 Dubal DP, Dhawale DS, More AM, et al. Synthesis and characterization of photosensitive $\mathrm{TiO}_{2}$ nanorods by controlled precipitation route. J Mater Sci, 2011, 46: 2288-2293

67 Wang Y, Shi R, Lin J, et al. Significant photocatalytic enhancement in methylene blue degradation of $\mathrm{TiO}_{2}$ photocatalysts via graphene-like carbon in situ hybridization. Appl Catal B-Environ, 2010, 100: 179-183

68 Liang $\mathrm{Y}$, Wang $\mathrm{H}$, Sanchez Casalongue $\mathrm{H}$, et al. $\mathrm{TiO}_{2}$ nanocrystals grown on graphene as advanced photocatalytic hybrid materials. Nano Res, 2010, 3: 701-705

69 Zou R, Zhang Z, Yu L, et al. A general approach for the growth of metal oxide nanorod arrays on graphene sheets and their applications. Chem Eur J, 2011, 17: 13912-13917

70 Xiao G, Shi C, Li L, et al. A 200-nm length $\mathrm{TiO}_{2}$ nanorod array with a diameter of $13 \mathrm{~nm}$ and areal density of $1100 \mu^{-2}$ for efficient perovskite solar cells. Ceramics Int, 2017, 43: 1253412539

71 Kim HS, Lee JW, Yantara N, et al. High efficiency solid-state sensitized solar cell-based on submicrometer rutile $\mathrm{TiO}_{2}$ nanorod and $\mathrm{CH}_{3} \mathrm{NH}_{3} \mathrm{PbI}_{3}$ perovskite sensitizer. Nano Lett, 2013, 13 : 2412-2417

72 Yuan L, Meng S, Zhou Y, et al. Controlled synthesis of anatase $\mathrm{TiO}_{2}$ nanotube and nanowire arrays via AAO template-based hydrolysis. J Mater Chem A, 2013, 1: 2552-2557

73 Attar AS, Ghamsari MS, Hajiesmaeilbaigi F, et al. Sol-gel template synthesis and characterization of aligned anatase- $\mathrm{TiO}_{2}$ nanorod arrays with different diameter. Mater Chem Phys, 2009, 113: $856-860$

74 Shao Z, Zhu W, Li Z, et al. One-step fabrication of CdS nanoparticle-sensitized $\mathrm{TiO}_{2}$ nanotube arrays via electrodeposition. J Phys Chem C, 2012, 116: 2438-2442

75 Tan W, Yin X, Zhou X, et al. Electrophoretic deposition of nanocrystalline $\mathrm{TiO}_{2}$ films on $\mathrm{Ti}$ substrates for use in flexible dyesensitized solar cells. Electrochim Acta, 2009, 54: 4467-4472

76 Limmer SJ, Chou TP, Cao GZ. A study on the growth of $\mathrm{TiO}_{2}$ nanorods using sol electrophoresis. J Mater Sci, 2004, 39: 895-901 
77 Gong D, Grimes CA, Varghese OK, et al. Titanium oxide nanotube arrays prepared by anodic oxidation. J Mater Res, 2011, 16: 3331-3334

78 Ozkan S, Mazare A, Schmuki P. Critical parameters and factors in the formation of spaced $\mathrm{TiO}_{2}$ nanotubes by self-organizing anodization. Electrochim Acta, 2018, 268: 435-447

79 Wang D, Liu Y, Yu B, et al. $\mathrm{TiO}_{2}$ nanotubes with tunable morphology, diameter, and length: synthesis and photo-electrical/ catalytic performance. Chem Mater, 2009, 21: 1198-1206

80 Wang W, Li G, Xia D, et al. Photocatalytic nanomaterials for solar-driven bacterial inactivation: recent progress and challenges. Environ Sci-Nano, 2017, 4: 782-799

81 Lee E, Hong JY, Kang H, et al. Synthesis of $\mathrm{TiO}_{2}$ nanorod-decorated graphene sheets and their highly efficient photocatalytic activities under visible-light irradiation. J Hazard Mater, 2012, 219-220: $13-18$

82 Liu S, Zeng TH, Hofmann M, et al. Antibacterial activity of graphite, graphite oxide, graphene oxide, and reduced graphene oxide: membrane and oxidative stress. ACS Nano, 2011, 5: 69716980

83 Akhavan O, Ghaderi E. Toxicity of graphene and graphene oxide nanowalls against bacteria. ACS Nano, 2010, 4: 5731-5736

84 Liu S, Hu M, Zeng TH, et al. Lateral dimension-dependent antibacterial activity of graphene oxide sheets. Langmuir, 2012, 28: 12364-12372

85 Akhavan O, Ghaderi E. Escherichia coli bacteria reduce graphene oxide to bactericidal graphene in a self-limiting manner. Carbon, 2012, 50: 1853-1860

86 Upadhyay RK, Soin N, Roy SS. Role of graphene/metal oxide composites as photocatalysts, adsorbents and disinfectants in water treatment: a review. RSC Adv, 2014, 4: 3823-3851

$87 \mathrm{Xu} \mathrm{C}, \mathrm{Xu} \mathrm{Y}$, Zhu J. Photocatalytic antifouling graphene oxidemediated hierarchical filtration membranes with potential applications on water purification. ACS Appl Mater Interfaces, 2014, 6: 16117-16123

88 Zeng X, Wang G, Liu Y, et al. Graphene-based antimicrobial nanomaterials: rational design and applications for water disinfection and microbial control. Environ Sci-Nano, 2017, 4: 22482266

89 Akhavan O, Ghaderi E. Photocatalytic reduction of graphene oxide nanosheets on $\mathrm{TiO}_{2}$ thin film for photoinactivation of bacteria in solar light irradiation. J Phys Chem C, 2009, 113: 20214-20220

90 Thakur S, Karak N. Tuning of sunlight-induced self-cleaning and self-healing attributes of an elastomeric nanocomposite by judicious compositional variation of the $\mathrm{TiO}_{2}$-reduced graphene oxide nanohybrid. J Mater Chem A, 2015, 3: 12334-12342

91 Santhosh C, Velmurugan V, Jacob G, et al. Role of nanomaterials in water treatment applications: A review. Chem Eng J, 2016, 306: 1116-1137

92 Feng Y, Liu L, Zhang J, et al. Photoactive antimicrobial nanomaterials. J Mater Chem B, 2017, 5: 8631-8652

93 Liu J, Liu L, Bai H, et al. Gram-scale production of graphene oxide- $\mathrm{TiO}_{2}$ nanorod composites: Towards high-activity photocatalytic materials. Appl Catal B-Environ, 2011, 106: 76-82

94 Wang S, Sun H, Ang HM, et al. Adsorptive remediation of environmental pollutants using novel graphene-based nanomaterials. Chem Eng J, 2013, 226: 336-347

95 Dreyer DR, Todd AD, Bielawski CW. Harnessing the chemistry of graphene oxide. Chem Soc Rev, 2014, 43: 5288
96 Zhang D, Fu L, Liao L, et al. Electrochemically functional graphene nanostructure and layer-by-layer nanocomposite incorporating adsorption of electroactive methylene blue. Electrochim Acta, 2012, 75: 71-79

97 Madadrang CJ, Kim HY, Gao G, et al. Adsorption behavior of EDTA-graphene oxide for $\mathrm{Pb}$ (II) removal. ACS Appl Mater Interfaces, 2012, 4: 1186-1193

98 Li Y, Du Q, Liu T, et al. Equilibrium, kinetic and thermodynamic studies on the adsorption of phenol onto graphene. Mater Res Bull, 2012, 47: 1898-1904

99 Wang R, Zhang $\mathrm{H}$, Wang W, et al. Improvement of dye-sensitized solar cells with $\mathrm{TiO}_{2}$ nanoarray- $\mathrm{TiO}_{2} /$ graphene nanocrystal composite film as photoanode. Acta Optica Sinica, 2013, 33: 1216001

100 Williams G, Seger B, Kamat PV. $\mathrm{TiO}_{2}$-graphene nanocomposites. UV-assisted photocatalytic reduction of graphene oxide. ACS Nano, 2008, 2: 1487-1491

101 Mor GK, Shankar K, Paulose $\mathrm{M}$, et al. Use of highly-ordered $\mathrm{TiO}_{2}$ nanotube arrays in dye-sensitized solar cells. Nano Lett, 2006, 6: 215-218

102 Sun WT, Yu Y, Pan HY, et al. CdS quantum dots sensitized $\mathrm{TiO}_{2}$ nanotube-array photoelectrodes. J Am Chem Soc, 2008, 130: $1124-1125$

103 Carnie MJ, Charbonneau C, Davies ML, et al. A one-step low temperature processing route for organolead halide perovskite solar cells. Chem Commun, 2013, 49: 7893

104 Zhang Z, Shi C, Lv K, et al. 200-nm long $\mathrm{TiO}_{2}$ nanorod arrays for efficient solid-state $\mathrm{PbS}$ quantum dot-sensitized solar cells. J Energy Chem, 2018, 27: 1214-1218

105 Jiang Q, Sheng X, Li Y, et al. Rutile $\mathrm{TiO}_{2}$ nanowire-based perovskite solar cells. Chem Commun, 2014, 50: 14720-14723

106 Feng X, Zhu K, Frank AJ, et al. Rapid charge transport in dyesensitized solar cells made from vertically aligned single-crystal rutile $\mathrm{TiO}_{2}$ nanowires. Angew Chem Int Ed, 2012, 51: 2727-2730

107 Mai L, Sheng J, Xu L, et al. One-dimensional hetero-nanostructures for rechargeable batteries. Acc Chem Res, 2018, 51: 950-959

108 Wei Q, An Q, Chen D, et al. One-pot synthesized bicontinuous hierarchical $\mathrm{Li}_{3} \mathrm{~V}_{2}\left(\mathrm{PO}_{4}\right)_{3} / \mathrm{C}$ mesoporous nanowires for high-rate and ultralong-life lithium-ion batteries. Nano Lett, 2014, 14: 1042-1048

109 Mai L, Tian X, Xu X, et al. Nanowire electrodes for electrochemical energy storage devices. Chem Rev, 2014, 114: 1182811862

110 Zhao Y, Han C, Yang J, et al. Stable alkali metal ion intercalation compounds as optimized metal oxide nanowire cathodes for lithium batteries. Nano Lett, 2015, 15: 2180-2185

111 Yan $\mathrm{M}$, He $\mathrm{P}$, Chen $\mathrm{Y}$, et al. Water-lubricated intercalation in $\mathrm{V}_{2} \mathrm{O}_{5} \cdot n \mathrm{H}_{2} \mathrm{O}$ for high-capacity and high-rate aqueous rechargeable zinc batteries. Adv Mater, 2018, 30: 1703725

112 An Q, Li Y, Deog Yoo H, et al. Graphene decorated vanadium oxide nanowire aerogel for long-cycle-life magnesium battery cathodes. Nano Energy, 2015, 18: 265-272

113 Zhang F, Qi L. Recent progress in self-supported metal oxide nanoarray electrodes for advanced lithium-ion batteries. Adv Sci, 2016, 3: 1600049

114 Kim H, Cho MY, Kim MH, et al. A novel high-energy hybrid supercapacitor with an anatase $\mathrm{TiO}_{2}$-reduced graphene oxide anode and an activated carbon cathode. Adv Energy Mater, 2013, 3: $1500-1506$ 
115 Ramadoss A, Kim GS, Kim SJ. Fabrication of reduced graphene oxide/ $\mathrm{TiO}_{2}$ nanorod/reduced graphene oxide hybrid nanostructures as electrode materials for supercapacitor applications. CrystEngComm, 2013, 15: 10222-10229

$116 \mathrm{Yu} \mathrm{X}$, Lin D, Li P, et al. Recent advances in the synthesis and energy applications of $\mathrm{TiO}_{2}$-graphene nanohybrids. Sol Energy Mater Sol Cells, 2017, 172: 252-269

Acknowledgements This work was supported by the National Natural
Science Foundation for Distinguished Young Scholars (51425204).

Author contributions Fan $\mathrm{Y}$ and Mai L proposed the topic and outline of the manuscript. Fan $\mathrm{Y}$ and Yu S collected the related information needed in writing the paper; Fan $\mathrm{Y}$ and Mai L co-wrote the manuscript. Hu G, Yu S and Xu L modified this manuscript. All authors discussed and commented on the manuscript.

Conflict of interest The authors declare no conflict of interest.

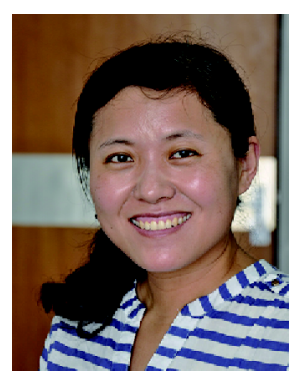

Yanhua Fan received her PhD degree from the Department of Chemistry and Chemical Engineering at Ocean University of China in 2009. She joined Shanghai Maritime University as lecturer in 2009. As a visiting scholar, she worked at the State Key Laboratory of Advanced Technology for Materials Synthesis and Processing in Wuhan University of Technology (WUT) from 2017 to 2018. Her research interest is mainly focused on the synthesis of nanostructured materials for environment and energy device applications.

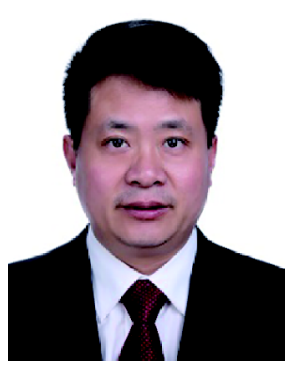

Liqiang Mai is Chair Professor of Materials Science and Engineering at WUT. He is Changjiang Scholar Professor, Distinguished Young Scholar of the National Science Foundation of China. He received his PhD from WUT in 2004 and carried out his postdoctoral research in the laboratory of Prof. Zhonglin Wang at Georgia Institute of Technology in 2006-2007. He worked as advanced research scholar in the laboratory of Prof. Charles M. Lieber at Harvard University in 2008-2011 and Prof. Peidong Yang's group at the University of California, Berkeley in 2017. His current research interests focus on nanomaterials and devices for energy storage.

\section{$\mathrm{TiO}_{2}$ 纳米阵列/石墨烯复合材料在水处理和能量转换与储存中的研究进展}

范艳华 ${ }^{1,2^{*}}$, 胡光武 ${ }^{2}$ 于帅芹 ${ }^{1}$, 麦立强 ${ }^{2}$, 徐林 $^{2}$

摘要 虽然 $\mathrm{TiO}_{2}$ 基纳米材料具有独特的化学物理特性, 在水处理和能量转换与储存中展现出广阔的前景, 但仍然存在一些局限性. 为了进 一步提高其光化学特性, 基于各种合成技术在基体表面制备一维的 $\mathrm{TiO}_{2}$ 纳米阵列通常与石墨烯进行复合. 这种复合涂层具有优异的光催 化性能以及优异的杀菌和吸附性能. 尤其是这种复合材料经过光催化处理后, 很容易回收再利用. 另外, 基体(尤其是柔性基体)表面的 $\mathrm{TiO}_{2}$ 纳米阵列/石墨烯复合涂层可以制备具有优异光电转化效率和光化学特性的柔性设备, 在能量转化和存储中具有潜在的应用价值. 